\title{
Vacuum ultraviolet photoionization cross section of the hydroxyl radical
}

Leah G. Dodson, John D. Savee, Samer Gozem, Linhan Shen, Anna I. Krylov, Craig A. Taatjes, David L. Osborn, and Mitchio Okumura

Citation: The Journal of Chemical Physics 148, 184302 (2018); doi: 10.1063/1.5024249

View online: https://doi.org/10.1063/1.5024249

View Table of Contents: http://aip.scitation.org/toc/jcp/148/18

Published by the American Institute of Physics

\section{PHYSICS TODAY}

WHITEPAPERS
ADVANCED LIGHT CURE ADHESIVES

READ NOW

Take a closer look at what these environmentally friendly adhesive systems can do
PRESENTED BY

Q. MASTERBOND' 


\title{
Vacuum ultraviolet photoionization cross section of the hydroxyl radical
}

\author{
Leah G. Dodson, ${ }^{1, a), b)}$ John D. Savee, ${ }^{2, c)}$ Samer Gozem, ${ }^{3, d)}$ Linhan Shen, ${ }^{1}$ Anna I. Krylov, ${ }^{3, a)}$ \\ Craig A. Taatjes, ${ }^{2}$ David L. Osborn, ${ }^{2, a)}$ and Mitchio Okumura ${ }^{1, a)}$ \\ ${ }^{1}$ Division of Chemistry and Chemical Engineering, California Institute of Technology, Pasadena, \\ California 91125, USA \\ ${ }^{2}$ Combustion Research Facility, Sandia National Laboratories, Livermore, California 94551, USA \\ ${ }^{3}$ Department of Chemistry, University of Southern California, Los Angeles, California 90089, USA
}

(Received 30 January 2018; accepted 17 April 2018; published online 8 May 2018)

\begin{abstract}
The absolute photoionization spectrum of the hydroxyl $(\mathrm{OH})$ radical from 12.513 to $14.213 \mathrm{eV}$ was measured by multiplexed photoionization mass spectrometry with time-resolved radical kinetics. Tunable vacuum ultraviolet (VUV) synchrotron radiation was generated at the Advanced Light Source. $\mathrm{OH}$ radicals were generated from the reaction of $\mathrm{O}\left({ }^{1} D\right)+\mathrm{H}_{2} \mathrm{O}$ in a flow reactor in $\mathrm{He}$ at 8 Torr. The initial $\mathrm{O}\left({ }^{1} D\right)$ concentration, where the atom was formed by pulsed laser photolysis of ozone, was determined from the measured depletion of a known concentration of ozone. Concentrations of $\mathrm{OH}$ and $\mathrm{O}\left({ }^{3} P\right)$ were obtained by fitting observed time traces with a kinetics model constructed with literature rate coefficients. The absolute cross section of $\mathrm{OH}$ was determined to be $\sigma(13.436 \mathrm{eV})=3.2$ $\pm 1.0 \mathrm{Mb}$ and $\sigma(14.193 \mathrm{eV})=4.7 \pm 1.6 \mathrm{Mb}$ relative to the known cross section for $\mathrm{O}\left({ }^{3} P\right)$ at $14.193 \mathrm{eV}$. The absolute photoionization spectrum was obtained by recording a spectrum at a resolution of $8 \mathrm{meV}$ (50 meV steps) and scaling to the single-energy cross sections. We computed the absolute VUV photoionization spectrum of $\mathrm{OH}$ and $\mathrm{O}\left({ }^{3} \mathrm{P}\right)$ using equation-of-motion coupled-cluster Dyson orbitals and a Coulomb photoelectron wave function and found good agreement with the observed absolute photoionization spectra. Published by AIP Publishing. https://doi.org/10.1063/1.5024249
\end{abstract}

\section{INTRODUCTION}

The hydroxyl $(\mathrm{OH})$ radical has been extensively studied due to its importance in atmospheric ${ }^{1-3}$ and combustion ${ }^{4}$ oxidation, and its presence in the interstellar medium. ${ }^{5}$ As a second-row hydride, $\mathrm{OH}$ has served as an important benchmark for fundamental studies of electronic spectroscopy and structure. The photoionization spectroscopy of $\mathrm{OH}$ in the vacuum ultraviolet (VUV) near its first ionization threshold remains less studied. Past spectroscopic experiments of the $\mathrm{OH}$ radical in the VUV used photoelectron, ${ }^{6-10}$ photoabsorption, ${ }^{11}$ and photoionization ${ }^{12-14}$ methods. Photoionization of $\mathrm{OH}\left(X^{2} \Pi\right)$ in the threshold region removes an electron from the valence $(2 p \pi)$ molecular orbital to form the ground electronic state of $\mathrm{OH}^{+}\left(X^{3} \Sigma^{-}\right)$. Wiedmann et al. used rotationally resolved zero electron kinetic energy pulsed field ionization photoelectron spectroscopy to measure the adiabatic ionization energy of $\mathrm{OH}$ as $I E=13.0170 \pm 0.0002 \mathrm{eV}^{6}$ Two studies have reported high-resolution relative photoionization spectra. ${ }^{12,13}$ Dehmer used a high-intensity helium continuum light source to create tunable VUV radiation and recorded spectra with resolutions of $0.07-0.23 \AA$. This

\footnotetext{
a)Authors to whom correspondence should be addressed: leah@jila.colorado. edu,krylov@usc.edu,dlosbor@sandia.gov, and mo@caltech.edu.

b) Current address: JILA and NIST, University of Colorado, Boulder, Colorado 80309, USA.

c)Current address: ABB, 3055 Orchard Dr., San Jose, CA 95134, USA.

d) Current address: Department of Chemistry, Georgia State University, Atlanta, Georgia 30303, USA.
}

spectrum agrees with a later spectrum from Cutler et al. ${ }^{13}$ obtained at $0.07 \AA$ A resolution. There have been two theoretical studies of the photoionization cross section of $\mathrm{OH}$. Stephens and McKoy calculated the absolute photoionization spectrum using multiplet-specific Hartree-Fock wave functions and numerical continuum orbitals obtained from the Schwinger variational method. ${ }^{15}$ Veseth and Kelly used an integral equation approach with many-body perturbation calculation of the complex polarizability to obtain the photoabsorption cross section, ${ }^{16}$ which should be an upper bound on the photoionization cross section. In the latter work, the continuum was described by a finite set of virtual orbitals. ${ }^{17}$ Both predicted spectra were sparse ( 0.1 a.u. or larger), and neither study provided much detail near the first ionization threshold. Until now, the absolute photoionization cross section of $\mathrm{OH}$ has not been measured.

The increasing use of tunable VUV radiation from synchrotrons has stimulated efforts to obtain absolute photoionization cross sections of free radical intermediates for both fundamental studies of photoionization and targeted studies of free radical chemistry. Synchrotron radiation has greatly enhanced the sensitivity and versatility of VUV mass spectrometry for studying the kinetics of gas phase free radicals. This technique, introduced by Bayes in $1972^{18}$ and developed by Gutman and others, ${ }^{19-26}$ has become an important tool for time-resolved gas phase kinetics investigations. The Sandia multiplexed photoionization mass spectrometer (MPIMS) couples the tunability, resolution, and high photon flux of synchrotron radiation with the detection sensitivity of mass spectrometry and the time resolution of pulsed-laser-photolysis to 
study the kinetics of gas-phase free radical reactions. ${ }^{27,28} \mathrm{In}$ these experiments, knowledge of photoionization cross sections allows one to determine neutral molecule concentrations from the signals of their corresponding cations.

In this paper, we combined photoionization spectroscopy with chemical kinetics to perform time-resolved photoionization experiments that generate $\mathrm{OH}$ from the $\mathrm{O}\left({ }^{1} D\right)+\mathrm{H}_{2} \mathrm{O}$ reaction. We obtained absolute photoionization cross sections for the $\mathrm{OH}$ radical at two photon energies by measuring the ion signal of $\mathrm{OH}(I E=13.0170 \mathrm{eV})^{6}$ relative to $\mathrm{O}\left({ }^{3} P\right)$ $(I E=13.6181 \mathrm{eV})^{29}$ while simultaneously measuring the ozone ion signal $(I E=12.52495 \mathrm{eV}) .{ }^{30}$ All three species have ionization energies (IEs) in the energy range of this experiment. The concentration of $\mathrm{OH}$ was quantified by modeling the time-dependent kinetics of $\mathrm{OH}, \mathrm{O}_{3}$, and $\mathrm{O}\left({ }^{3} P\right)$ and estimating the initial absolute concentration of $\mathrm{O}\left({ }^{1} D\right)$. We computed the absolute cross sections for $\mathrm{OH}$ and $\mathrm{O}\left({ }^{3} P\right)$ using equationof-motion coupled cluster (EOM-CC) Dyson orbitals and a Coulomb wave description of the photoelectron wave function and compared the computational results with experimentally obtained photoionization cross sections.

\section{METHODS}

\section{A. Experiment}

The MPIMS has been described in detail in previous publications. ${ }^{27,28}$ The experiments conducted here were similar to our prior work. ${ }^{31}$ Initial concentrations of approximately $10^{12} \mathrm{~cm}^{-3} \mathrm{OH}$ radicals were produced in a slow flow reactor by flash photolysis of $\mathrm{O}_{3} / \mathrm{H}_{2} \mathrm{O} / \mathrm{O}_{2}$ mixtures with added xenon (photoionization calibration standard) highly diluted in helium at 8 Torr and room temperature. UV radiation at $248 \mathrm{~nm}$ from a $\mathrm{KrF}$ excimer laser propagated along the axis of the flow cell to photodissociate $\mathrm{O}_{3}$, forming $\mathrm{O}\left({ }^{1} D\right)$ atoms, which reacted with $\mathrm{H}_{2} \mathrm{O}$ to yield $\mathrm{OH}$. Time-resolved measurements were made by sampling the reaction mixture after a portion of it expanded through a small orifice in the side of the reactor tube. Neutral species in the expanding gas jet were ionized by tunable VUV synchrotron radiation generated at the Chemical Dynamics Beamline of the Advanced Light Source of Lawrence Berkeley National Laboratory. The resulting cations were analyzed with orthogonal acceleration time-of-flight (OA-TOF) mass spectrometry. Reactants, radicals, and products were detected as their parent ion $\mathrm{m} / \mathrm{z}$.

The reactor comprised a $1.05 \mathrm{~cm}$ inner diameter, $62 \mathrm{~cm}$ long quartz tube coated with an amorphous fluoroplastic resin (DuPont AF 400S2-100-1). Gases were introduced upstream of the $600 \mu \mathrm{m}$ diameter sampling orifice. Helium (Matheson Tri-Gas, 99.9999\%) was introduced into the reactor using a calibrated mass flow controller (MKS Instruments). A saturated stream of water vapor was introduced through a calibrated mass flow controller by flowing He through a fritted bubbler of distilled, purified water immersed in a temperature-controlled bath. Ozone was generated from pure oxygen (Matheson TriGas, $99.998 \%$ ) by a commercial corona discharge ozone generator (OzoneLab Instruments). The ozone concentration was measured in the gas line after the ozone generator using an ozone monitor (2B Technologies Model 202). The combined
$\mathrm{O}_{3} / \mathrm{O}_{2}$ volume flow rate was measured with a variable rotameter (King Instruments Company $45 \mathrm{sccm}$ full scale, systematic error $\pm 4 \%$ full scale). Although the ozone concentration exceeded the rated range of the ozone monitor, we found that the measured ozone concentrations were still accurate (see the supplementary material). A cylinder of xenon diluted in $\mathrm{He}$ $(0.974 \pm 0.001 \%)$ was prepared, and a small flow $(0.5 \pm 0.2$ SCCM) was added to the flow reactor as a photoionization reference gas. The total flow of all gases through the reactor was $200 \pm 5 \mathrm{SCCM}$. The total pressure was maintained at 8.00 \pm 0.04 Torr, measured with a capacitance manometer (MKS Baratron).

Typical starting mole fractions of reagent gases were $1 \%$ $\mathrm{O}_{2}, 1 \% \mathrm{H}_{2} \mathrm{O}, 100 \mathrm{ppm} \mathrm{O}_{3}$, and $20 \mathrm{ppm} \mathrm{Xe} \mathrm{(photoionization}$ cross section reference gas) with the balance composed of He. The $\mathrm{O}_{3}$ was photolyzed by an unfocused excimer laser pulse (Coherent COMPex Pro $110 \mathrm{KrF}, 248 \mathrm{~nm}, 15 \mathrm{~ns}, 4 \mathrm{~Hz}$ ) at laser fluences of either 18 or $12 \mathrm{~mJ} \mathrm{~cm}^{-2}$ pulse ${ }^{-1}$ (the lower fluence was obtained by inserting a wire mesh filter). Timeresolved radical signals were measured by recording complete OA-TOF mass spectra at $50 \mathrm{kHz}$. We summed every $10 \mathrm{spec}-$ tra to obtain a mass spectrum every $0.2 \mathrm{~ms}$. With each laser shot, we acquired a two-dimensional data set (ion counts as a function of mass-to-charge ratio $\mathrm{m} / \mathrm{z}$ and reaction time relative to the excimer laser pulse). We averaged data from 2000 to 5000 laser shots for the kinetics experiments. To record photoionization spectra, we scanned the photon energy over the range $12.513-14.213 \mathrm{eV}$ in steps of $0.05 \mathrm{eV}$ (spectral resolution of $\Delta E_{\mathrm{FWHM}}=8 \mathrm{meV}$ ), averaging 50 laser shots at each photon energy. Such scans generated three-dimensional data sets (i.e., ion counts as a function of $\mathrm{m} / \mathrm{z}$, reaction time, and photoionization energy).

Several instrument effects were treated as described previously. ${ }^{31}$ The mass-dependent sensitivity of the OA-TOF to the ion signal was measured empirically, which was necessary to compare the ion signal of $\mathrm{OH}$ with that of the reference atoms $\left[\mathrm{O}\left({ }^{3} \mathrm{P}\right)\right.$ and $\left.\mathrm{Xe}\right]$ in order to obtain photoionization cross sections. ${ }^{32}$ Additionally, in order to compare the time-dependent ion signals with a quantitative kinetics model, we needed to incorporate the finite instrument time-response function caused by Maxwell-Boltzmann sampling in the experiment ${ }^{33,34}$ and the small gradient in the photolysis yield along the flow axis, into our kinetics model. In this work, we measured the instrument response function and photolysis gradient under conditions with the lower photolysis laser fluence $\left(12 \mathrm{~mJ} \mathrm{~cm}^{-2}\right.$ pulse $\left.^{-1}\right)$. These conditions created less radical recycling, which enabled a clearer measurement of the latter two instrument effects.

The high concentrations of water in the reactor led to background ion counts from the wings of the strong $\mathrm{m} / \mathrm{z}$ $=18\left(\mathrm{H}_{2} \mathrm{O}^{+}\right)$signal in both the $\mathrm{m} / \mathrm{z}=17\left(\mathrm{OH}^{+}\right)$and $\mathrm{m} / \mathrm{z}$ $=16\left(\mathrm{O}^{+}\right)$channels. The observed ion signals at these masses were corrected by subtracting the average of the pre-photolysis ion signal from -19 to $-1 \mathrm{~ms}$. We assumed that the concentrations of neutral species yielding these background ions did not change upon photolysis. These background signals were small but statistically significant, typically on the order of $1 \%$ of the peak counts for $\mathrm{OH}$ and $6 \%$ of the peak counts for $\mathrm{O}\left({ }^{3} P\right)$. 


\section{B. Theory}

We computed absolute photoionization cross sections for the $\mathrm{O}\left({ }^{3} P\right)$ and the $\mathrm{OH}$ radicals using correlated Dyson orbitals and a Coulomb wave description of the photoelectron. Dyson orbitals $\left[\phi_{I F}^{d}(\mathbf{1})\right]$ are expressed as an overlap between the initial ( $N$ electron) and final $(N-1$ electron) wave functions of the molecule in photoionization/photodetachment processes, ${ }^{35-37}$

$$
\phi_{I F}^{d}(\mathbf{1})=\sqrt{N} \int \Psi_{I}^{N}(\mathbf{1}, \ldots, \mathbf{n}) \Psi_{F}^{N-1}(\mathbf{2}, \ldots, \mathbf{n}) d \mathbf{2} \ldots d \mathbf{n} .
$$

They can be interpreted as the state of the photoelectron before it is ionized. Within the sudden approximation and strong orthogonality assumptions, Dyson orbitals contain all the information about correlated many-electron wave functions necessary to compute the absolute photoionization cross section $\left(\sigma_{k}\right),{ }^{38}$

$$
\begin{aligned}
D_{k}^{I F} & =\mathbf{u}\left\langle\phi_{I F}^{d}|\mathbf{r}| \Psi_{k}^{c o n t}\right\rangle, \\
\sigma_{k} & =\frac{4 \pi^{2} k E}{c}\left|D_{k}^{I F}\right|^{2},
\end{aligned}
$$

where $\mathbf{u}$ is a unit vector in the direction of the polarization of light, $\mathbf{r}$ is the dipole moment operator, $D_{k}^{I F}$ is the photoelectron dipole moment matrix element, and $\Psi^{\text {cont }}$ is the continuum wave function of the ejected photoelectron. In Eq. (3), $k, E$, and $c$ correspond to the magnitude of the photoelectron wave vector, the energy of ionizing radiation, and the speed of light, respectively.

Here we compute Dyson orbitals using two different variants of equation-of-motion coupled-cluster with single and double excitations (EOM-CCSD) ${ }^{39}$ In the EOM-CC formalism, one needs to define a reference state and a specific type of the EOM operator connecting the reference and the target states. ${ }^{37,40}$ For photoionization or photodetachment from closed-shell species, the most obvious choice is to use the closed-shell initial state as a reference and to describe the ionized/detached states by EOM-IP (EOM for ionization potentials, where the EOM operators remove one electron from the reference). ${ }^{41,42}$ For photoionization or photodetachment from open-shell doublet species producing a closed-shell state, one can employ the reference state corresponding to the ionized closed-shell state and use EOM-EA (EOM for electron attachment, where the EOM operators add an electron to the reference) to describe the initial doublet state. ${ }^{43}$ In the case of photoionization of $\mathrm{O}\left({ }^{3} P\right)$ and $\mathrm{OH}\left({ }^{2} \Pi\right)$, however, both the initial and the final states are of open-shell character (see Fig. 1). Consequently, the selection of the most appropriate EOMCCSD method is not as obvious as in the case when either the initial or final state is a closed shell. For $\mathrm{O}\left({ }^{3} P\right)$, one can use the neutral triplet $\left({ }^{3} P\right)$ state as the CCSD reference state and describe the final ionized quartet $\left({ }^{4} S\right)$ state with EOMIP-CCSD. Alternatively, one can use the ${ }^{4} S$ state as the CCSD reference state and describe the ${ }^{3} P$ state with EOM-EA-CCSD. Similarly, for the $\mathrm{OH}$ radical, it is possible to describe the initial neutral doublet state $\left(X^{2} \Pi\right)$ with CCSD and the final ionized triplet state $\left(X^{3} \Sigma^{-}\right)$with EOM-IP-CCSD, or conversely the $X^{3} \Sigma^{-}$state with CCSD and $X^{2} \Pi$ with EOM-EA-CCSD. For both $\mathrm{O}\left({ }^{3} P\right)$ and $\mathrm{OH}$, we expect the EOM-EA-CCSD approach to be more reliable than EOM-IP-CCSD due to there being

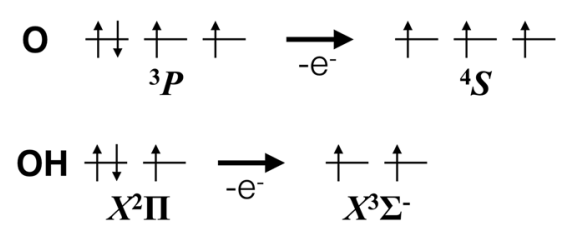

FIG. 1. Electronic configurations for $\mathrm{O}$ and $\mathrm{OH}$ before and after ionization.

multiple configurations of the ${ }^{3} P$ state in $\mathrm{O}$ and the $X^{2} \Pi$ state in OH. However, as shown in Figs. S4 and S5 of the supplementary material, EOM-EA-CCSD and EOM-IP-CCSD give virtually identical results for both species, indicating that both approaches are robust. The same supporting figures also indicate that calculations using an ROHF or UHF reference give almost identical cross sections. An aug-cc-pVTZ basis set was employed in all calculations.

EOM-CCSD Dyson orbitals for $\mathrm{O}$ and $\mathrm{OH}$ are shown in Fig. 2. Their shapes qualitatively agree with Koopmans theorem predictions. The photoionization cross sections were computed by using a Coulomb wave to describe the final continuum state of the photoelectron. The Coulomb wave accounts for the electrostatic interaction of the photoelectron with a point $(+1)$ charge located at the centroid of the Dyson orbital. This simple model has been shown to produce absolute photoionization spectra of neutral atoms such as $\mathrm{He}$ and $\mathrm{Ne}$ and small molecular systems such as $\mathrm{H}_{2}$ and $\mathrm{H}_{2} \mathrm{O}$ that are in excellent agreement with experiment. ${ }^{41}$ Therefore, we expect Coulomb waves to be suitable for describing the continuum state in photoionization from $\mathrm{O}\left({ }^{3} P\right)$ and $\mathrm{OH}$.

Another quantity needed for calculating absolute photoionization cross sections is the ionization energy. Here we use the experimental values: $13.6181 \mathrm{eV}$ for $\mathrm{O}\left({ }^{3} P\right)$ (evaluated by $\mathrm{Lide}^{29}$ ) and $13.0170 \mathrm{eV}$ for $\mathrm{OH}$ (from the photoelectron spectrum reported by Wiedmann et al. ${ }^{6}$ ).

Note that while in some systems it is important to account for electronic and spin degeneracies by multiplying the cross section calculated for a single electron by an integer degeneracy factor, ${ }^{41,44}$ for $\mathrm{O}\left({ }^{3} \mathrm{P}\right)$ and $\mathrm{OH}$ radicals this factor is simply one since only one electron can be ionized to give the ${ }^{4} S$ state in $\mathrm{O}$ and the $X^{3} \Sigma^{-}$state in $\mathrm{OH}$.

Dyson orbitals were computed using Q-Chem ${ }^{45}$ and photoionization cross sections were computed with ezDyson. ${ }^{44}$ In the case of the $\mathrm{OH}$ radical, we accounted for Franck-Condon factors (FCFs) by using the equilibrium geometries and frequencies for the $X^{2} \Pi$ and $X^{3} \Sigma^{-}$states obtained with density functional theory (DFT), using the $\omega$ B97X-D functional ${ }^{46}$ and the aug-cc-pVTZ basis set. The FCFs were computed within the double-harmonic approximation using ezSpectrum. ${ }^{47}$
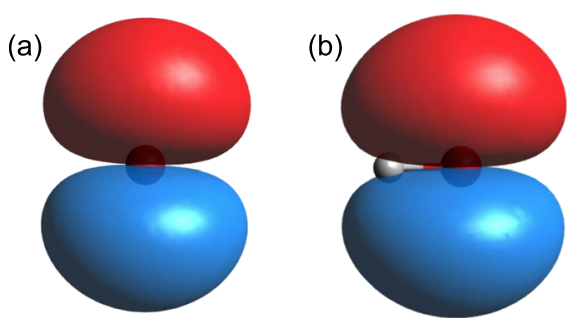

FIG. 2. Dyson orbitals for (a) O and (b) OH computed with EOM-IP-CCSD. 


\section{RESULTS}

\section{A. Experiments}

Sixteen experiments were conducted, varying conditions such as initial $\mathrm{O}_{3}$ or $\mathrm{H}_{2} \mathrm{O}$ concentration, excimer laser fluence, and/or the VUV photon energy. Table I lists the VUV photon energy and species concentrations for each experiment. Nine experiments were performed at a photon energy of $13.436 \mathrm{eV}$, and five experiments were performed at a photon energy of $14.193 \mathrm{eV}$. Radical concentrations were reduced by attenuating the laser beam in three experiments (13-15). In Experiment 16, the VUV photon energy was scanned to obtain the relative photoionization spectrum. We detected photoionization signals of $\mathrm{OH}, \mathrm{O}_{3}$, and $\mathrm{O}\left({ }^{3} \mathrm{P}\right)$ at their parent $\mathrm{m} / \mathrm{z}$ ratios.

\section{B. Kinetics modeling}

Photolysis of $\mathrm{O}_{3}$ at $248 \mathrm{~nm}$ generated oxygen atoms promptly by direct photodissociation,

$$
\begin{aligned}
\mathrm{O}_{3}+h v(248 \mathrm{~nm}) & \rightarrow \mathrm{O}\left({ }^{1} D\right)+\mathrm{O}_{2}, \\
\mathrm{O}_{3}+h v(248 \mathrm{~nm}) & \rightarrow \mathrm{O}\left({ }^{3} P\right)+\mathrm{O}_{2} .
\end{aligned}
$$

The $\mathrm{O}\left({ }^{1} D\right)$ yield $\Phi_{\mathrm{O} 3,248}\left({ }^{1} D\right)(\mathrm{R} 1 \mathrm{a})$ is $90 \% \pm 9 \%$ of reaction (R1). ${ }^{48-50}$ The $\mathrm{O}\left({ }^{1} D\right)$ atoms reacted with $\mathrm{H}_{2} \mathrm{O}$ to form two $\mathrm{OH}$ radicals in $<0.2 \mathrm{~ms}$,

$$
\mathrm{O}\left({ }^{1} D\right)+\mathrm{H}_{2} \mathrm{O} \rightarrow 2 \mathrm{OH} .
$$

However, a significant fraction of the $\mathrm{O}\left({ }^{1} D\right)$ atoms underwent a competing process, collisional quenching, primarily by $\mathrm{O}_{2}$,

$$
\mathrm{O}\left({ }^{1} D\right)+\mathrm{O}_{2} \rightarrow \mathrm{O}\left({ }^{3} P\right)+\mathrm{O}_{2} .
$$

Approximately 5\%-40\% were quenched through reaction (R3), depending on the $\mathrm{O}_{2}$ concentration.

Under our conditions, $\mathrm{OH}$ primarily reacted with $\mathrm{O}\left({ }^{3} P\right)$ at early times $(t<5 \mathrm{~ms})$ until $\mathrm{O}\left({ }^{3} P\right)$ was depleted,

$$
\mathrm{OH}+\mathrm{O}\left({ }^{3} P\right) \rightarrow \mathrm{H}+\mathrm{O}_{2} .
$$

At longer times, the $\mathrm{OH}$ self-reaction became the dominant removal mechanism,

$$
\begin{aligned}
& \mathrm{OH}+\mathrm{OH} \rightarrow \mathrm{H}_{2} \mathrm{O}+\mathrm{O}\left({ }^{3} P\right), \\
& \mathrm{OH}+\mathrm{OH} \stackrel{\mathrm{M}}{\longrightarrow} \mathrm{H}_{2} \mathrm{O}_{2},
\end{aligned}
$$

where, in these experiments, $\mathrm{M}=\mathrm{He}$. Reaction (R4) regenerated $\mathrm{OH}$ radicals since the $\mathrm{H}$ atoms reacted quickly with $\mathrm{O}_{3}$,

$$
\mathrm{H}+\mathrm{O}_{3} \rightarrow \mathrm{OH}+\mathrm{O}_{2} .
$$

Reaction (R6) effectively slowed the apparent $\mathrm{OH}$ decay rate as long as the $\mathrm{O}\left({ }^{3} P\right)$ atom concentration remained high enough to generate sufficient $\mathrm{H}$ atoms by reaction (R4). Reactions (R3)-(R6) largely determined the time-dependence of the $\mathrm{OH}$ concentrations.

We modeled the reaction kinetics using a numerical program $\left(\right.$ Kintecus $\left.^{51}\right)$. The full kinetics model is listed in Table II. All of the rate coefficients were obtained from the NASA Panel for Data Evaluation of Chemical Kinetics and Photochemical Data. ${ }^{50}$ In addition to reactions (R1)-(R6), we included 12 other reactions in the model, but these had a minor effect on the kinetics of the relevant species. For example, the

\begin{tabular}{|c|c|c|c|c|c|c|}
\hline Experiment & $\begin{array}{c}\text { Photon } \\
\text { energy }(\mathrm{eV})\end{array}$ & $\begin{array}{c}N_{\mathrm{O} 3}\left(/ 10^{13}\right) \\
\mathrm{cm}^{-3}\end{array}$ & $\begin{array}{c}N_{\mathrm{O} 2}\left(/ 10^{15}\right) \\
\mathrm{cm}^{-3}\end{array}$ & $\begin{array}{c}N_{\mathrm{H} 2 \mathrm{O}}\left(/ 10^{15}\right) \\
\mathrm{cm}^{-3}\end{array}$ & $\begin{array}{c}N_{\mathrm{O}(1 D)}(t=0) \\
\left(/ 10^{12}\right) \mathrm{cm}^{-3}\end{array}$ & $\begin{array}{c}N_{\mathrm{OH}}(v=0)(\text { peak }) \\
\left(/ 10^{12}\right) \mathrm{cm}-3\end{array}$ \\
\hline $1^{\mathrm{a}}$ & 13.113 & $3.6 \pm 0.3$ & 3.55 & $\ldots$ & $10.8 \pm 0.6$ & $\ldots$ \\
\hline 2 & 13.436 & $2.6 \pm 0.3$ & 2.06 & 2.24 & $6.0 \pm 0.3$ & $8.2 \pm 2.3$ \\
\hline 3 & 13.436 & $3.9 \pm 0.3$ & 3.53 & 2.17 & $9.1 \pm 0.5$ & $10.8 \pm 3.1$ \\
\hline 4 & 13.436 & $6.1 \pm 0.3$ & 5.11 & 2.23 & $14.2 \pm 0.8$ & $14.8 \pm 4.3$ \\
\hline 5 & 13.436 & $4.4 \pm 0.3$ & 3.65 & 2.17 & $10.4 \pm 0.6$ & $12.2 \pm 3.5$ \\
\hline 6 & 13.436 & $1.5 \pm 0.3$ & 1.14 & 2.22 & $3.5 \pm 0.22$ & $5.4 \pm 1.5$ \\
\hline 7 & 13.436 & $0.9 \pm 0.3$ & 0.69 & 2.23 & $2.1 \pm 0.1$ & $3.4 \pm 0.9$ \\
\hline 8 & 13.436 & $2.5 \pm 0.3$ & 1.98 & 1.03 & $5.9 \pm 0.3$ & $6.9 \pm 2.0$ \\
\hline 9 & 13.436 & $2.6 \pm 0.3$ & 2.00 & 0.52 & $5.9 \pm 0.3$ & $5.2 \pm 1.5$ \\
\hline 10 & 14.193 & $0.9 \pm 0.3$ & 0.80 & 2.20 & $2.1 \pm 0.1$ & $3.4 \pm 1.5$ \\
\hline 11 & 14.193 & $6.4 \pm 0.3$ & 5.24 & 2.23 & $13.5 \pm 0.7$ & $14.0 \pm 3.6$ \\
\hline 12 & 14.193 & $4.1 \pm 0.3$ & 3.09 & 2.20 & $9.4 \pm 0.5$ & $11.6 \pm 3.4$ \\
\hline $13^{\mathrm{b}}$ & 14.193 & $4.1 \pm 0.3$ & 3.09 & 2.19 & $5.5 \pm 0.3$ & $7.0 \pm 2.0$ \\
\hline $14^{\mathrm{b}}$ & 13.436 & $0.9 \pm 0.3$ & 0.68 & 2.20 & $1.33 \pm 0.07$ & $2.2 \pm 1.0$ \\
\hline $15^{\mathrm{b}}$ & 14.193 & $0.9 \pm 0.3$ & 0.68 & 2.23 & $1.33 \pm 0.07$ & $2.2 \pm 0.6$ \\
\hline 16 & $12.513-14.213$ & $3.9 \pm 0.3$ & 2.94 & 2.23 & $\ldots$ & $\ldots$ \\
\hline
\end{tabular}

TABLE I. Photon energies and relevant concentrations for all experiments. All experiments were performed at $298 \mathrm{~K}, 8$ Torr pressure, and $200 \mathrm{sccm}$ total flow rate. $N_{\mathrm{O}(1 D)}(t=0)$ is the initial density of $\mathrm{O}\left({ }^{1} D\right)$ atoms formed from photolysis of $\mathrm{O}_{3}$, from the measured photodissociation of ozone and expected quantum yield. The error bars in $N_{\mathrm{O}(1 D)}(t=0)$ comprise the uncertainty in the fit from the depletion data and the systematic errors. The $\mathrm{OH}$ concentration is the peak $\mathrm{OH}$ value from each model simulation, given with the uncertainty in $N_{\mathrm{OH}}(v=0)$ (peak), which is computed from the uncertainty in the rate constants and reactant concentrations. Photon energies are uncertain to $\pm 8 \mathrm{meV}$.

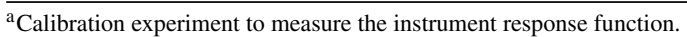

${ }^{\mathrm{b}}$ Experiments conducted with a mesh attenuator to reduce the excimer laser fluence. 
TABLE II. The reactions used to simulate the concentration-dependent profiles for $\mathrm{OH}$ and $\mathrm{O}_{3}$. Pressuredependent rate constants are for 8 Torr of He. All rate constants are taken from the NASA Data Evaluation, ${ }^{50}$ unless otherwise noted.

\begin{tabular}{|c|c|c|c|}
\hline & & $k_{298 \mathrm{~K}}\left(\mathrm{~cm}^{3} \mathrm{~s}^{-1}\right)$ & Notes \\
\hline \multirow{2}{*}{ (1) } & $\mathrm{O}_{3}+h v(248 \mathrm{~nm}) \rightarrow \mathrm{O}\left({ }^{1} D\right)+\mathrm{O}_{2}$ & $\Phi_{\mathrm{O} 3,248}\left({ }^{1} D\right)=90 \% \pm 9 \%$ & (R1a) \\
\hline & $\rightarrow \mathrm{O}\left({ }^{3} P\right)+\mathrm{O}_{2}$ & $\Phi_{\mathrm{O} 3,248}\left({ }^{3} P\right)=10 \% \pm 9 \%$ & (R1b) \\
\hline (2) & $\mathrm{O}\left({ }^{1} D\right)+\mathrm{H}_{2} \mathrm{O} \rightarrow 2 \mathrm{OH}$ & $2.0_{-0.1}^{+0.2} \times 10^{-10}$ & (R2) \\
\hline (3) & $\mathrm{O}\left({ }^{1} D\right)+\mathrm{O}_{2} \rightarrow \mathrm{O}\left({ }^{3} P\right)+\mathrm{O}_{2}$ & $3.95 \pm 0.4 \times 10^{-11}$ & (R3) \\
\hline (4) & $\mathrm{OH}+\mathrm{O}\left({ }^{3} P\right) \rightarrow \mathrm{H}+\mathrm{O}_{2}$ & $3.3_{-0.4}^{+0.5} \times 10^{-11}$ & (R4) \\
\hline \multirow{2}{*}{ (5) } & $\mathrm{OH}+\mathrm{OH} \rightarrow \mathrm{H}_{2} \mathrm{O}+\mathrm{O}\left({ }^{3} P\right)$ & $1.8_{-0.4}^{+0.5} \times 10^{-12}$ & $(\mathrm{R} 5 \mathrm{a})^{\mathrm{a}}$ \\
\hline & $\stackrel{\mathrm{M}}{\longrightarrow} \mathrm{H}_{2} \mathrm{O}_{2}$ & $9.6 \times 10^{-14}$ & $(\mathrm{R} 5 \mathrm{~b})^{\mathrm{a}}$ \\
\hline (6) & $\mathrm{H}+\mathrm{O}_{3} \rightarrow \mathrm{OH}+\mathrm{O}_{2}$ & $2.9 \pm 0.3 \times 10^{-11}$ & (R6) \\
\hline (7) & $\mathrm{OH}+\mathrm{O}_{3} \rightarrow \mathrm{HO}_{2}+\mathrm{O}_{2}$ & $7.3_{-1.0}^{+1.1} \times 10^{-14}$ & \\
\hline (8) & $\mathrm{O}\left({ }^{3} P\right)+\mathrm{O}_{3} \rightarrow 2 \mathrm{O}_{2}$ & $8.0_{-0.7}^{+0.8} \times 10^{-15}$ & \\
\hline (9) & $\mathrm{H}+\mathrm{O}_{2} \stackrel{\mathrm{M}}{\longrightarrow} \mathrm{HO}_{2}$ & $4.7 \pm 0.3 \times 10^{-15}$ & $\mathrm{~b}$ \\
\hline \multirow{2}{*}{ (10) } & $\mathrm{O}\left({ }^{1} D\right)+\mathrm{O}_{3} \rightarrow 2 \mathrm{O}_{2}$ & $1.2 \pm 0.2 \times 10^{-10}$ & \\
\hline & $\rightarrow 2 \mathrm{O}\left({ }^{3} P\right)+\mathrm{O}_{2}$ & $1.2 \pm 0.2 \times 10^{-10}$ & \\
\hline (11) & $\mathrm{O}\left({ }^{3} \mathrm{P}\right)+\mathrm{O}_{2} \stackrel{\mathrm{M}}{\longrightarrow} \mathrm{O}_{3}$ & $8.6 \pm 0.5 \times 10^{-17}$ & c \\
\hline (12) & $\mathrm{OH}+\mathrm{HO}_{2} \rightarrow \mathrm{H}_{2} \mathrm{O}+\mathrm{O}_{2}$ & $1.1_{-0.1}^{+0.2} \times 10^{-10}$ & \\
\hline (13) & $\mathrm{OH}+\mathrm{H}_{2} \mathrm{O}_{2} \rightarrow \mathrm{HO}_{2}+\mathrm{H}_{2} \mathrm{O}$ & $1.8_{-0.2}^{+0.3} \times 10^{-12}$ & \\
\hline (14) & $\mathrm{O}\left({ }^{3} P\right)+\mathrm{HO}_{2} \rightarrow \mathrm{OH}+\mathrm{O}_{2}$ & $5.9 \pm 0.3 \times 10^{-11}$ & \\
\hline \multirow[t]{2}{*}{ (15) } & $\mathrm{O}\left({ }^{3} P\right)+\mathrm{H}_{2} \mathrm{O}_{2} \rightarrow \mathrm{OH}+\mathrm{HO}_{2}$ & $1.7 \pm 0.3 \times 10^{-15}$ & \\
\hline & $\mathrm{H}+\mathrm{HO}_{2} \rightarrow 2 \mathrm{OH}$ & $7.2_{-1.2}^{+1.4} \times 10^{-11}$ & \\
\hline \multirow[t]{2}{*}{ (16) } & $\left.\rightarrow \mathrm{O}^{3} P\right)+\mathrm{H}_{2} \mathrm{O}$ & $1.6_{-0.5}^{+0.8} \times 10^{-12}$ & \\
\hline & $\rightarrow \mathrm{H}_{2}+\mathrm{O}_{2}$ & $6.9_{-2.0}^{+2.8} \times 10^{-12}$ & \\
\hline (17) & $\mathrm{HO}_{2}+\mathrm{HO}_{2} \rightarrow \mathrm{H}_{2} \mathrm{O}_{2}+\mathrm{O}_{2}$ & $1.4 \pm 0.2 \times 10^{-12}$ & \\
\hline (18) & $\mathrm{O}_{3}+\mathrm{HO}_{2} \rightarrow \mathrm{OH}+2 \mathrm{O}_{2}$ & $1.9_{-0.2}^{+0.3} \times 10^{-15}$ & \\
\hline
\end{tabular}

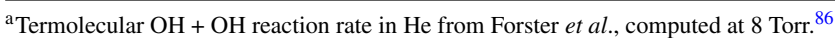

${ }^{\mathrm{b}}$ Termolecular $\mathrm{H}+\mathrm{O}_{2}$ reaction rate in He from Michael et al., computed at 8 Torr. ${ }^{87}$

${ }^{\mathrm{c}}$ Termolecular $\mathrm{O}\left({ }^{3} P\right)+\mathrm{O}_{2}$ reaction rate in He from Huie et al., computed at 8 Torr. ${ }^{88}$

reaction of $\mathrm{OH}$ with $\mathrm{O}_{3}$ was not fast enough to affect the time profiles of either species on our time scale. The timedependent concentrations of $\mathrm{OH}, \mathrm{O}_{3}$, and $\mathrm{O}\left({ }^{3} P\right)$ obtained from the model were convolved with the instrument response function for comparison with the experiment, as discussed previously. ${ }^{31}$

$\mathrm{OH}$ radicals could also react with the surface of the reactor. In previous work, we measured wall loss rates of the lessreactive $\mathrm{HO}_{2}$ radical of $k_{\mathrm{L}} \approx 5-12 \mathrm{~s}^{-1}$ in the same reactor with the same type of coating. ${ }^{31}$ Here we determined a first order $\mathrm{OH}$ wall loss experimentally.

\section{Observed kinetics}

Examples of the time-dependent $\mathrm{O}_{3}{ }^{+}, \mathrm{OH}^{+}$, and $\mathrm{O}^{+}$ signals are shown in Figs. 3-5. Photolysis led to a nearinstantaneous depletion of typically $13 \%-24 \%$ of the initial $\mathrm{O}_{3}$. After this initial drop, the ozone ion signal subsequently decayed at a slower rate (over approximately $60 \mathrm{~ms}$ ) as chemical reactions removed additional $\mathrm{O}_{3}$. The $\mathrm{OH}^{+}$signal rose promptly to a peak in the first $0.5 \mathrm{~ms}$, followed by a slow decay (approximately $20 \mathrm{~ms}$ lifetime). The $\mathrm{O}^{+}$signal, arising from $\mathrm{O}\left({ }^{3} P\right)$, also rose promptly and then decayed with a lifetime of $<10 \mathrm{~ms}$, somewhat faster than the $\mathrm{OH}$ decay.

\section{Ozone photolysis}

Figure 3(a) shows an example of the observed $\mathrm{O}_{3}$ signal measured at $\mathrm{m} / z=48$ in Experiment 4 (Table I). The instantaneous depletion from photolysis was $23.3 \% \pm 0.3 \%$ [Fig. 3(b)], in good agreement with the $\mathrm{O}_{3}$ depletion of $24 \%$ estimated from the measured laser fluence, the $\mathrm{O}_{3}$ concentration, and the $\mathrm{O}_{3}$ absorption cross section $\left[\sigma_{\mathrm{O} 3 \text {,abs }}(248 \mathrm{~nm})\right.$ $\left.=1.08 \times 10^{-17} \mathrm{~cm}^{2}\right] .{ }^{50}$ The subsequent secondary decay of $\mathrm{O}_{3}$, which continued to $60 \mathrm{~ms}$ as seen in Fig. 3(a), occurred primarily by reactions with $\mathrm{H}$ atoms [reaction (R6)] at early times and with the remaining $\mathrm{OH}$ at later times. The kinetics model (in the absence of $\mathrm{OH}$ wall loss) slightly overpredicted the initial loss rate at early times $(t<10 \mathrm{~ms})$ and underpredicted the loss rate at longer times.

\section{2. $O\left({ }^{1} D\right)$ atoms}

In order to model the time dependence of the concentration of $\mathrm{OH}$ radicals, $N_{\mathrm{OH}}(t)$, we needed to determine the initial $\mathrm{O}\left({ }^{1} D\right)$ atom concentrations. $\mathrm{O}\left({ }^{1} D\right)$ atoms could not be observed directly because their expected lifetime $(\sim 1 \mu \mathrm{s})$ was much shorter than the instrument temporal resolution. Instead, we estimated the initial $\mathrm{O}\left({ }^{1} D\right)$ atom concentrations $N_{\mathrm{O}(1 D), 0}$ from the measured $\mathrm{O}_{3}$ concentration, the observed fractional depletion of $\mathrm{O}_{3}$ caused by photolysis, and the known $\mathrm{O}\left({ }^{1} D\right)$ 


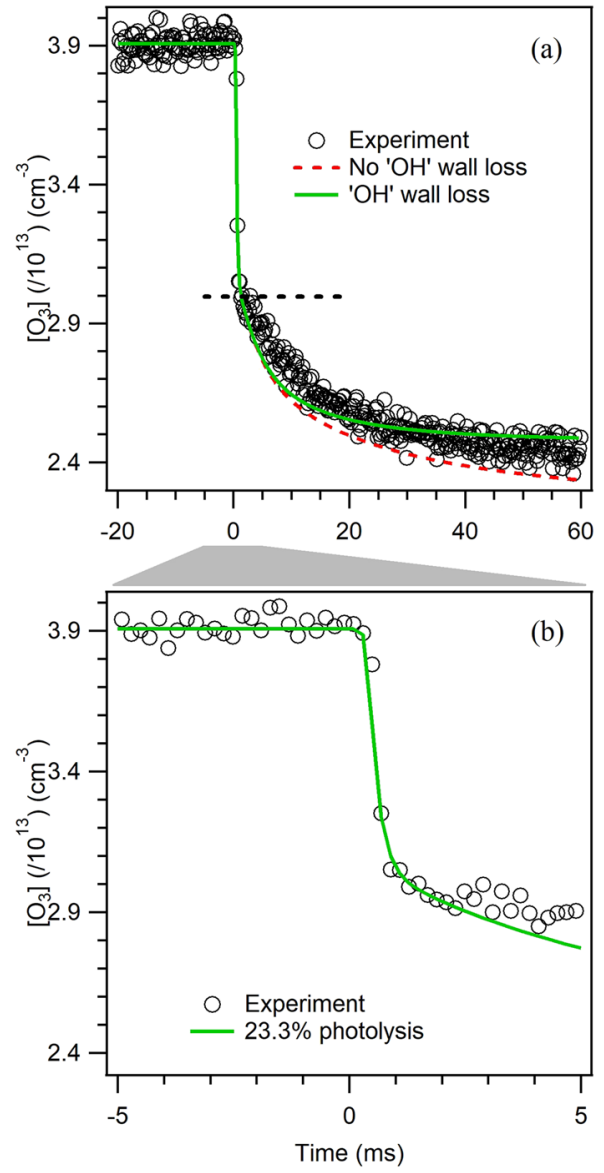

FIG. 3. Observed $\mathrm{O}_{3}$ depletion with excimer photolysis at $t=0 \mathrm{~ms}$. (a) Entire kinetics trace of the $\mathrm{O}_{3}$ concentration. The subsequent removal of $\mathrm{O}_{3}$ is primarily by reaction with $\mathrm{H}$ atoms at early times and by reaction with $\mathrm{OH}$ at longer times. The red dashed line shows the kinetics model without inclusion of $\mathrm{OH}$ wall loss. The green solid line shows the kinetics model with an $\mathrm{OH}$ wall loss rate of $29 \mathrm{~s}^{-1}$. The black dashed line shows the $23.3 \%$ depletion from photolysis. (b) Expansion of the kinetics trace about $t=0 \mathrm{~ms}$. The initial depletion at $t=0 \mathrm{~ms}$ is due to photolysis, convolved with the temporal resolution of the spectrometer. The green line shows a fit using an initial photolytic depletion of $23.3 \% \pm 0.1 \%$ and subsequent depletion by secondary chemistry that includes wall loss. Data taken from Experiment 4.

quantum yield [reaction (R1a)]. Values are given in Table I. For example, in Experiment 4, given the $23.3 \% \pm 0.3 \%$ depletion of the $\mathrm{O}_{3}$ concentration of $6.1 \pm 0.3 \times 10^{13} \mathrm{~cm}^{-3}$ [Fig. 3(a)], the prompt $\mathrm{O}\left({ }^{1} D\right)$ concentration, prior to quenching or reaction, was $14.2 \pm 0.8 \times 10^{12} \mathrm{~cm}^{-3}$.

Table I lists the calculated initial $N_{\mathrm{O}(1 D)}(t=0)$ concentration for each experiment. In Experiments 1-12, for which the same excimer laser settings were used, the observed ozone depletions were similar and ranged from $21.0 \% \pm 0.1 \%$ to $23.8 \% \pm 0.2 \%$. In Experiments 13-15, we used an attenuator to achieve lower radical concentrations and observed smaller ozone depletions of $\sim 14 \%$. By changing the ozone concentration and/or using an attenuator, we varied initial $\mathrm{O}\left({ }^{1} D\right)$ atom concentrations over the range $1-14 \times 10^{12} \mathrm{~cm}^{-3}$.

\section{3. $\mathrm{OH}$ radicals}

Figure 4(a) shows the time-dependent $\mathrm{OH}^{+}$signal from Experiment $4(13.436 \mathrm{eV})$ from 0 to $60 \mathrm{~ms}$. There was a rapid rise in $\mathrm{OH}$ upon $\mathrm{O}_{3}$ photolysis that reached a peak at $t<1 \mathrm{~ms}$, followed by a decay that approached the baseline after $60 \mathrm{~ms}$.
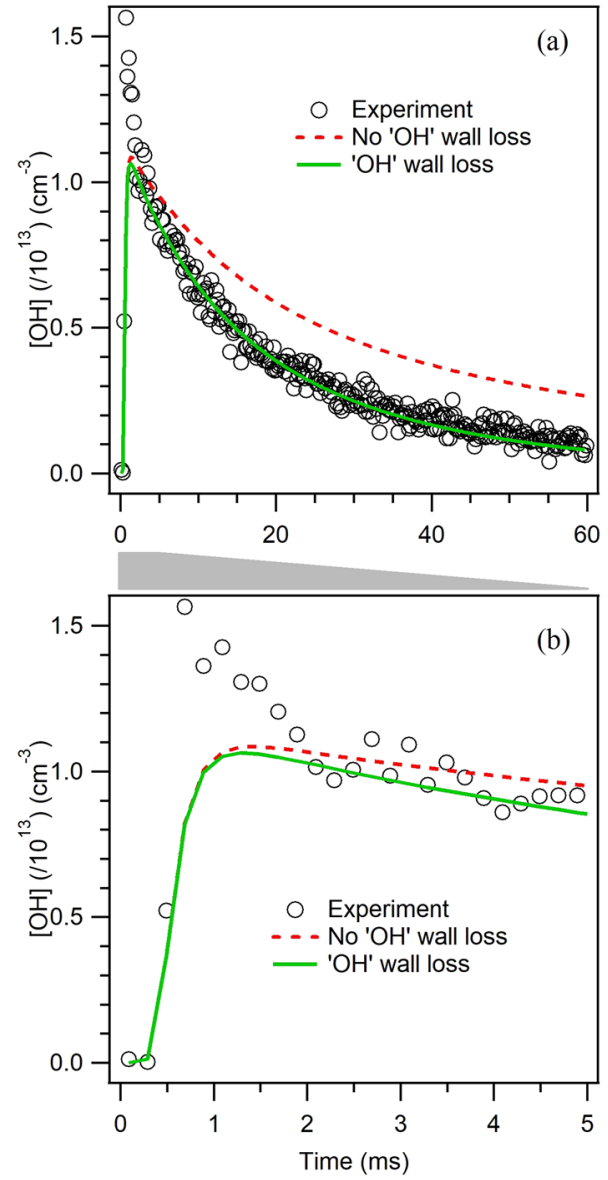

FIG. 4. Observed $\mathrm{OH}$ decay. (a) demonstrates the entire kinetics trace from 0 to $60 \mathrm{~ms}$. The red dashed line shows the simulated kinetics model in the absence of any adjustments to the kinetics model. The green solid line shows the kinetics model fitted with an $\mathrm{OH}$ wall loss rate $\left(29 \pm 6 \mathrm{~s}^{-1}\right)$. The fit was performed from 5 to $20 \mathrm{~ms}$, which excluded the initial spike (attributed to relaxation of vibrationally excited $\mathrm{OH}$, observed in the first few milliseconds). (b) is the same data, plotted from 0 to $5 \mathrm{~ms}$, showing that the early feature presumably caused by $\mathrm{OH}(v>0)$ decays within $2 \mathrm{~ms}$. Data taken from Experiment 4.

The modeled $\mathrm{OH}$ time profile shown in Fig. 4(a) (red dashed line) agreed qualitatively with the observed time-dependence. The reaction of $\mathrm{O}\left({ }^{1} D\right)$ atoms with $\mathrm{H}_{2} \mathrm{O}$ formed two $\mathrm{OH}$

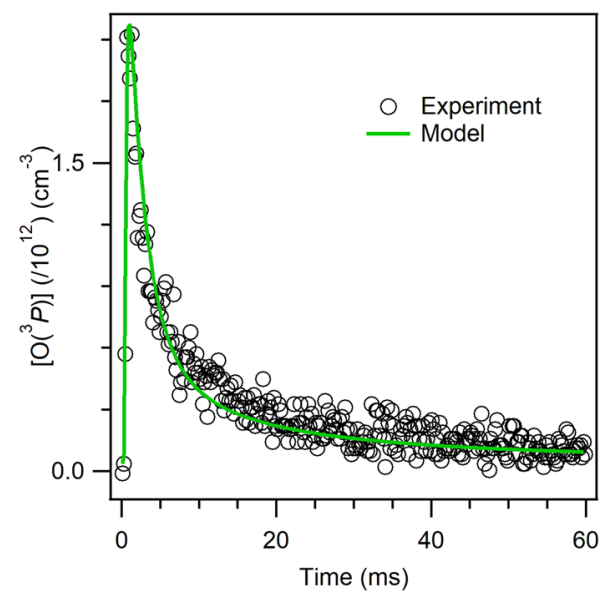

FIG. 5. Observed $\mathrm{O}\left({ }^{3} P\right)$ decay. The absolute concentrations of the data points (open points) are scaled to fit the kinetics model (green line). Data taken from Experiment 11. 
radicals [reaction (R2)] but competed with quenching, primarily by $\mathrm{O}_{2}$. In our models, quenching of $\mathrm{O}\left({ }^{1} D\right)$ reduced the $\mathrm{OH}$ yield by $10 \%-40 \%$, depending on the gas composition and pressure. The modeled peak $\mathrm{OH}$ concentrations obtained from our estimated $\mathrm{O}\left({ }^{1} D\right)$ concentrations are given in Table I.

In order to scale the observed ion signal to an absolute $N_{\mathrm{OH}}$ concentration, we needed to match the observed ion signal time trace to the model prediction; however, in all experiments, the observed time-dependence of the $\mathrm{OH}^{+}$signal differed from the model in two significant ways. First, the observed decay was non-biexponential; at early times, the $\mathrm{OH}^{+}$signal decayed rapidly [within $2 \mathrm{~ms}$, Fig. 4(b)]. Second, at later times (over the range $2-60 \mathrm{~ms}$ ), the observed decay rate more closely matched the modeled decay rate but was still slightly faster than predicted.

Assuming our model is not missing any critical reactions of ground state $\mathrm{OH}$, the $\mathrm{OH}$ signal from 0 to $2 \mathrm{~ms}$ shown in Fig. 4(b) could not arise exclusively from the ground state $\mathrm{OH}$ because the signal decayed too quickly. The fastest loss process for $\mathrm{OH}(v=0)$ was reaction with transient $\mathrm{O}\left({ }^{3} P\right)$, giving $\mathrm{OH}$ a lifetime of at least $8 \mathrm{~ms}$ at the highest $\mathrm{O}\left({ }^{3} P\right)$ concentration. However, we expected that a significant fraction of the nascent $\mathrm{OH}$ produced via reaction (R2) was vibrationally excited. Previous experiments on reactions of ${ }^{16} \mathrm{O}\left({ }^{1} D\right)$ with isotopically labeled $\mathrm{H}_{2}{ }^{18} \mathrm{O}$ revealed that, of the two $\mathrm{OH}$ radicals formed from reaction (R2), the heavier $\mathrm{OH}$ radical product is formed cold, with nearly all of its population in $\mathrm{OH}(v=0),{ }^{52-57}$ while a significant fraction of the lighter $\mathrm{OH}$ radical is in $\mathrm{OH}(v=1)$ $(29 \%)$ and $\mathrm{OH}(v \geq 2)(30 \%) .{ }^{57}$ Under our conditions, $\mathrm{OH}(v \geq$ 1) would be rapidly quenched by $\mathrm{H}_{2} \mathrm{O}$,

$$
\mathrm{OH}(v)+\mathrm{H}_{2} \mathrm{O} \rightarrow \mathrm{OH}(v=0)+\mathrm{H}_{2} \mathrm{O} .
$$

$\mathrm{OH}(v=1)$ would have a lifetime of $0.05 \mathrm{~ms}\left[k_{19}(v=1)\right.$ $\left.=1.1 \pm 0.7 \times 10^{-11} \mathrm{~cm}^{3} \mathrm{~s}^{-1}\right] \cdot{ }^{58}$ Relaxation by $\mathrm{O}_{2}$ would be slower,

$$
\mathrm{OH}(v)+\mathrm{O}_{2} \rightarrow \mathrm{OH}(v=0)+\mathrm{O}_{2},
$$

with a lifetime for $\mathrm{OH}(v=1)$ of $0.75 \mathrm{~ms}\left[k_{20}(v=1)=7.5 \pm 2.2\right.$ $\left.\times 10^{-12} \mathrm{~cm}^{3} \mathrm{~s}^{-1}\right] .{ }^{59}$ The somewhat longer apparent decay time $\left(\tau_{\text {obs }} \approx 1 \mathrm{~ms}\right.$ ) seen in Fig. 4(b) can be attributed to a combination of cascading kinetics from a range of initial vibrational states and the instrument response time (on the order of $1 \mathrm{~ms}$ ). All reactive loss channels were orders of magnitude slower, even for vibrationally hot $\mathrm{OH}$, so the $\mathrm{OH}(v)$ decayed strictly to ground state $\mathrm{OH}$.

An early peak due to hot $\mathrm{OH}$ could only be observed if vibrationally excited $\mathrm{OH}$ radicals had photoionization cross sections larger than that of $\mathrm{OH}(v=0)$ at this photon energy. The sharp onset at the photoionization threshold suggests that the Franck Condon factors are nearly unity, resulting in little difference in cross sections. However, we might expect enhanced cross sections for hot $\mathrm{OH}$ since excitation of $\mathrm{OH}$ $(v \geq 1)$ at $13.436 \mathrm{eV}$ could excite resonances due to Rydberg levels converging to $\mathrm{OH}^{+}(v=1)$ that later autoionize. We found evidence for such an effect in preliminary experiments that we performed under similar conditions on the $\mathrm{O}\left({ }^{1} D\right)+\mathrm{H}_{2}$ reaction system, which also produced a large nascent population of vibrationally excited $\mathrm{OH}$; these results are presented in the supplementary material. When we photoionized $\mathrm{OH}$ at $13.103 \mathrm{eV}$, we observed a similar biexponential decay, with an early peak that decayed rapidly. However, at $12.588 \mathrm{eV}$, which is $0.429 \mathrm{eV}$ below the ionization energy of $\mathrm{OH}$, ionization of vibrationally excited $\mathrm{OH}$ is energetically allowed because the vibrational energy of $\mathrm{OH}(v=1)$ is $0.442 \mathrm{eV}$. We detected a significant population of $\mathrm{OH}(v>0)$ that decayed on the same time scale $(2 \mathrm{~ms})$ as the early peak.

We therefore assigned the large peak in the early $\mathrm{OH}^{+}$ signal to $\mathrm{OH}(v \geq 1)$. Once all of the $\mathrm{OH}(v>0)$ had relaxed to the $v=0$ state, the $\mathrm{OH}^{+}$signal should correspond to that of the predicted concentration $N_{\mathrm{OH}}(t=0)$. As can be seen in Fig. 4(b), the early signal decayed to a plateau by $2 \mathrm{~ms}$, and the two decay time scales were readily distinguished. We therefore fit the modeled $\mathrm{OH}(v=0)$ concentration using the ion signal time trace beyond 2 ms [Fig. 4(b)].

The second discrepancy concerned the decay of $\mathrm{OH}(\mathrm{v}=0)$ over the range 2-60 ms. The measured lifetime of the $\mathrm{OH}(v=0)$ signal was about $13 \mathrm{~ms}$-slightly shorter than the modeled lifetime of about $16 \mathrm{~ms}$. We attributed this discrepancy to loss of $\mathrm{OH}$ by heterogeneous reactions on the reactor wall, which was coated with fluorocarbon. To test this assumption, we conducted several experiments where we varied the initial conditions of the reaction system, in particular varying the initial $\mathrm{OH}$ radical density over the range $0.2-1.5$ $\times 10^{13} \mathrm{~cm}^{-3}$. We modeled heterogeneous loss of $\mathrm{OH}$ as a firstorder loss process in our kinetics model and independently fit the model to each data set to quantify the $\mathrm{OH}$ wall loss rate. The average heterogeneous wall loss rate and its standard deviation across all experiments were $k_{\mathrm{wall}}=29 \pm 3 \mathrm{~s}^{-1}$. To account for existing uncertainty in the kinetics model (for example, uncertainty in the $\mathrm{OH}$ self-reaction rate constant), we used a Monte Carlo simulation, varying all rate constants by their evaluated uncertainties, to evaluate the total uncertainty in the first order $\mathrm{OH}$ wall loss rate. The result of this procedure gives a final result for the empirical $\mathrm{OH}$ wall-reaction rate constant of $k_{\text {wall }}$ $=29 \pm 6 \mathrm{~s}^{-1}$, for this reactor. The OH wall loss rate described above is 3-6 times larger than the wall loss of the less-reactive $\mathrm{HO}_{2}$ radical that we measured previously in a reactor with a similar coating. ${ }^{31}$

Figure 4(a) (green line) shows the modeled decay of $\mathrm{OH}$ when incorporating the fitted wall loss rate. We did not attempt to fit the sharp spike in signal at early times [the component attributed to $\mathrm{OH}(v \geq 1)$ ]. The model including $\mathrm{OH}$ wall loss also improved the fit of the ozone time dependence, predicting slightly less depletion of $\mathrm{O}_{3}$ at long times [Fig. 3(b), green line] than the model without $\mathrm{OH}$ wall loss (red dashed line).

\section{4. $O\left({ }^{3} P\right)$ atoms}

$\mathrm{O}\left({ }^{3} P\right)$ atoms formed largely from both the initial photolysis and the collisional deactivation of $\mathrm{O}\left({ }^{1} D\right)$ were also observed at a photon energy of $14.193 \mathrm{eV}$. The $\mathrm{O}\left({ }^{3} P\right)$ signal rose quickly and then decayed rapidly with a lifetime of approximately $4 \mathrm{~ms}$, primarily by reacting with $\mathrm{OH}$. Figure 5 shows the measured $\mathrm{O}\left({ }^{3} P\right)$ signal, scaled relative to the kinetics model for Experiment $11(14.193 \mathrm{eV})$. The agreement between the observed and modeled $N_{\mathrm{O}(3 P)}(t)$ is satisfactory. The heterogeneous wall loss of $\mathrm{O}\left({ }^{3} P\right)$ on the reactor walls did not 
contribute significantly to the $\mathrm{O}\left({ }^{3} \mathrm{P}\right)$ loss because $\mathrm{O}\left({ }^{3} \mathrm{P}\right)$ atoms reacted too rapidly with $\mathrm{OH}$.

\section{Experimental cross section and spectrum}

To measure the absolute photoionization cross section of $\mathrm{OH}$, we need the relative signals and concentrations of $\mathrm{OH}$ with respect to a reference species whose photoionization cross section is known. We measured the absolute photoionization cross section of $\mathrm{OH}$ at two photon energies: 13.436 and $14.193 \mathrm{eV}$, using the cross sections of $\mathrm{O}\left({ }^{3} P\right)$ and $\mathrm{Xe}$ as absolute references, as discussed below. The absolute photoionization spectrum of $\mathrm{OH}$ was obtained by recording the relative photoionization spectrum from 12.513 to $14.213 \mathrm{eV}$ and scaling to the absolute $\mathrm{OH}$ photoionization cross sections measured at $13.436 \mathrm{eV}$ and $14.193 \mathrm{eV}$.

$\mathrm{O}\left({ }^{3} P\right)$, with an ionization energy of $13.6181 \mathrm{eV},{ }^{29}$ was ionized only in experiments conducted at $14.193 \mathrm{eV}$. Angel and Samson measured the absolute photoionization cross section for $\mathrm{O}\left({ }^{3} P\right)$ to be $\sigma_{\mathrm{O}(3 P)}(14.25 \mathrm{eV})=3.1 \pm 0.3 \mathrm{Mb} .{ }^{60} \mathrm{We}$ assumed that the cross section is the same at $14.193 \mathrm{eV}$ because the $\mathrm{O}\left({ }^{3} P\right)$ spectrum is flat in this region. Xe, with an ionization energy of $12.1298 \mathrm{eV},{ }^{29}$ was ionized at both experimental energies, with the absolute cross sections $\sigma_{\mathrm{Xe}}(13.436 \mathrm{eV})$ $=65.3 \pm 1 \mathrm{Mb}$ and $\sigma_{\mathrm{Xe}}(14.2 \mathrm{eV})=64.2 \pm 1 \mathrm{Mb}$, evaluated by Samson and Stolte. ${ }^{61}$

We determined the absolute concentrations of $\mathrm{OH}$ and $\mathrm{O}\left({ }^{3} \mathrm{P}\right)$ in the reactor by modeling the time-dependent reaction kinetics, in combination with the estimated initial $\mathrm{O}\left({ }^{1} D\right)$ concentration formed from the photolysis of ozone. At $14.193 \mathrm{eV}$, we then determined the photoionization cross section of $\mathrm{OH}$ relative to that of $\mathrm{O}\left({ }^{3} \mathrm{P}\right)$ from the relative magnitudes of the time-dependent ion signals and the modeled concentrations. At $13.436 \mathrm{eV}$, we again used the modeled $\mathrm{OH}$ kinetics and the $\mathrm{OH}$ ion signal to obtain the photoionization cross section of $\mathrm{OH}$, this time relative to Xe that was added to the gas mixture. The xenon concentration was determined from the flow conditions. Due to instrumental limitations at the synchrotron at the time of the experiment, we were able to record the absolute xenon concentration with high precision but not high accuracy. We therefore used the relative xenon signals at 13.436 and $14.193 \mathrm{eV}$ to calibrate the $\mathrm{OH}$ cross section at $13.436 \mathrm{eV}$ relative to the $\mathrm{O}\left({ }^{3} P\right)$ measurements at $14.193 \mathrm{eV}$.

\section{Experimental measurement of cross sections}

The $\mathrm{OH}$ photoionization cross section $\left[\sigma_{\mathrm{OH}}(E)\right]$ was measured relative to the reference atom cross section $\left[\sigma_{r e f}(E)\right]$ using the following equation:

$$
\sigma_{\mathrm{OH}}(E)=\sigma_{r e f}(E) \times \frac{\alpha_{r e f} \times f_{r e f}}{\alpha_{\mathrm{OH}} \times f_{\mathrm{OH}, 17}} \times \frac{\left\langle\frac{S_{\mathrm{OH}}(E, t)}{N_{\mathrm{OH}}(t)}\right\rangle_{\Delta t}}{\left\langle\frac{S_{r e f}(E, t)}{N_{\text {ref }}(t)}\right\rangle_{\Delta t^{\prime}}},
$$

where $\alpha_{i}$ is the mass discrimination factor, $f_{i}$ is the fractional isotopic abundance of each species, $S_{i}(E)$ is the measured ion signal at photon energy $E$ [after subtracting the time-independent background for $\mathrm{OH}$ and $\left.\mathrm{O}\left({ }^{3} P\right)\right]$, and $N_{i}$ is the modeled concentration of species $i$. The angle brackets, \langle\rangle , indicate that a weighted average was performed over time windows $\Delta t$ and $\Delta t^{\prime}$, for $\mathrm{OH}$ and the reference species, respectively. The mass discrimination factor, $\alpha_{i}=\left(m_{i}\right)^{n}$, was described by Savee et al., ${ }^{32}$ where $m_{i}$ is the mass-to-charge ratio for the ion and $n$ is a parameter that is fit to the massdependence of the ion detection efficiency. In this work, we measured $n=1.0$ at these conditions.

We computed the weighted average of the ratio of the background-subtracted time-dependent $\mathrm{OH}$ signal $\left[S_{\mathrm{OH}}(E, t)\right]$ to the simulated $\mathrm{OH}$ reaction profile $\left[N_{\mathrm{OH}}(t)\right]$ over the time window $\Delta t(5-40 \mathrm{~ms})$, as shown in the following equation:

$$
\left\langle\frac{S_{\mathrm{OH}}(E)}{N_{\mathrm{OH}}}\right\rangle_{\Delta t}=\frac{\sum_{t=5 \mathrm{~ms}}^{40 \mathrm{~ms}}\left(\frac{S_{\mathrm{OH}}(E, t)}{N_{\mathrm{OH}}(t)} w(t)\right)}{\sum_{t=5 \mathrm{~ms}}^{40 \mathrm{~ms}} w(t)} .
$$

The lower bound $\mathrm{t}=5 \mathrm{~ms}$ was chosen to allow complete relaxation of $\mathrm{OH}$ radicals that were initially vibrationally excited (see the supplementary material). The weighting of each time point $[w(t)]$ was computed using the following equation:

$$
w(t)=\left(\frac{1}{S_{\mathrm{OH}}(E, t)}+\frac{R S E^{2}\left(N_{\mathrm{OH}}(t)\right)}{N_{\mathrm{OH}}^{2}(t)}\right)^{-1} .
$$

The uncertainty in the ion signal obeyed Poisson statistics, and the standard deviation was approximated as $\sqrt{S_{\mathrm{OH}}(E, t)}$ (background ions counts were small), leading to the first term in Eq. (6). These standard deviations were less than $2 \%$ of the ion signal over the time window. The relative standard error $(R S E)$ in the modeled time-dependent $\mathrm{OH}$ concentration $\left[R S E\left(N_{\mathrm{OH}}(t)\right)\right]$ was computed for each set of experimental conditions by varying all rate constants in Table II using Monte Carlo sampling (1000 iterations) from a normal distribution of the standard deviations of the rate constants, as listed in the table. $\operatorname{RSE}\left(N_{\mathrm{OH}}(t)\right)$ ranged from $0.8 \%$ to $5.9 \%$ of the peak $N_{\mathrm{OH}}$. Overall, the average was weighted toward shorter times.

We obtained a similar expression for the reference species by performing a weighted average over a time window $\Delta t^{\prime}$. Here, the limits of the summation depend on the reference compound. At $14.193 \mathrm{eV}, \mathrm{O}\left({ }^{3} P\right)$ served as the reference atom, and we averaged the background-subtracted $\mathrm{O}\left({ }^{3} P\right)$ signal $\left[S_{r e f}(E, t)\right]$, divided by the simulated $\mathrm{O}\left({ }^{3} P\right)$ kinetics $\left[N_{r e f}(t)\right]$ from 1 to $10 \mathrm{~ms}$, computing the weights in a similar manner to Eqs. (5) and (6), in order to determine the $\mathrm{OH}$ cross section at $14.193 \mathrm{eV}$ and to measure the xenon concentration in the reactor. At $13.436 \mathrm{eV}$, xenon served as the reference atom. The reference xenon signal was constant in time and not background-subtracted because it was chemically inert. We averaged the ratio of the signal to the measured xenon concentration from -20 to $130 \mathrm{~ms}$.

Ideally, we would have calibrated the absolute photoionization cross sections at both wavelengths using the photoionization cross section of Xe. However, we were not able to determine the absolute concentration of Xe in these experiments with sufficient accuracy. The flow rate (0.5 SCCM) of the $\mathrm{Xe}$ gas mixture into the reactor was at the lower limit of the available mass flow controller (MKS Model 1179A). This flow resulted in a large uncertainty $( \pm 40 \%)$ based on the 
manufacturer's specification. We found in practice that we could measure this flow with a precision of $\pm 1 \%$, consistent across all experiments, but we could not be confident of the absolute accuracy. To avoid biasing our results, we determined the absolute Xe concentration by comparing the $\mathrm{Xe}^{+}$ and $\mathrm{O}^{+}$ion signals using the known $\mathrm{Xe}$ and $\mathrm{O}\left({ }^{3} \mathrm{P}\right)$ photoionization cross sections at $14.193 \mathrm{eV}$. From our measurements of the Xe concentration, we found that the xenon concentration estimated from the xenon flow rate had to be corrected by a factor of $c_{\mathrm{Xe}}=0.89 \% \pm 0.04 \%$. The derivation is detailed in the supplementary material. This calibration was used to determine the Xe concentrations in the experiments at $13.436 \mathrm{eV}$, a photon energy below the ionization energy of $\mathrm{O}\left({ }^{3} P\right)$.

Using Eq. (4), we obtained the absolute cross section for $\mathrm{OH}$ independently for each experiment listed in Table I. The analysis of the uncertainty of each experiment is given in the supplementary material. The largest source of error for this measurement was the uncertainty in the modeled $\left.\mathrm{O}^{3} \mathrm{P}\right)$ concentrations, which was largely due to uncertainty in the yield of $\mathrm{O}\left({ }^{1} D\right)$ atoms from ozone photolysis, $\Phi_{\mathrm{O}, 248}\left({ }^{1} D\right)$. We then computed a weighted average cross section and uncertainty at each of the two photon energies (see Table III).

\section{Absolute photoionization spectrum of $\mathrm{OH}$ and $\mathrm{O}\left({ }^{3} \mathrm{P}\right)$}

The relative $\mathrm{OH}$ photoionization spectrum was collected by scanning the synchrotron photon energy from 12.513 to $14.213 \mathrm{eV}$ in $0.05 \mathrm{eV}$ steps using the reaction conditions listed in Table I (Experiment 16). The data, shown in Fig. 6, were integrated over 0-60 ms, with the background ion signal measured from -19 to $-1 \mathrm{~ms}$ subtracted. This relative signal was normalized to the VUV photon flux, measured at each energy using a photodiode (SXUV100). The absolute $\mathrm{OH}$ photoionization spectrum (Fig. 6) was then obtained by scaling this spectrum to the two absolute cross sections measured above (Table III). The tabulated spectrum is reported in the supplementary material.

We also obtained the absolute VUV photoionization spectrum of $\mathrm{O}\left({ }^{3} P\right)$ in the same experiment. The black open circles in Fig. 7 are the $\mathrm{O}\left({ }^{3} P\right)$ photoionization spectrum measured in this work, scaled by the literature absolute photoionization cross section of $\mathrm{O}\left({ }^{3} P\right), \sigma_{\mathrm{O}(3 P)}(14.25 \mathrm{eV})=3.1 \mathrm{Mb}^{60}$ The signal-to-noise ratio for the $\mathrm{O}\left({ }^{3} \mathrm{P}\right)$ spectrum was lower than

TABLE III. Photoionization cross sections for the reference compounds used in this work and the average single-energy $\mathrm{OH}$ cross sections measured here. Xenon cross sections were taken from the work of Samson and Stolte. ${ }^{61}$ The literature $\mathrm{O}\left({ }^{3} P\right)$ cross section was taken from the work of Angel and Samson, for a photon energy equal to $14.25 \mathrm{eV}{ }^{60}$ The reported $\mathrm{OH}$ cross sections were determined in the present work and uncertainties come from the systematic and random errors in the measurement.

\begin{tabular}{lccc}
\hline \hline Photon energy $(\mathrm{eV})$ & $\mathrm{Xe}(\mathrm{Mb})^{\mathrm{a}}$ & $\mathrm{O}\left({ }^{3} P\right)(\mathrm{Mb})^{\mathrm{b}}$ & $\mathrm{OH}(\mathrm{Mb})^{\mathrm{c}}$ \\
\hline 13.436 & 65.3 & $\ldots$ & $3.2 \pm 1.0$ \\
14.193 & 63.7 & 3.1 & $4.7 \pm 1.6$ \\
\hline \hline
\end{tabular}

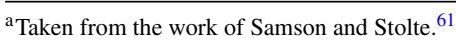

${ }^{\mathrm{b}}$ Taken from the work Angel and Samson. ${ }^{60}$

${ }^{\mathrm{c}}$ Present work.

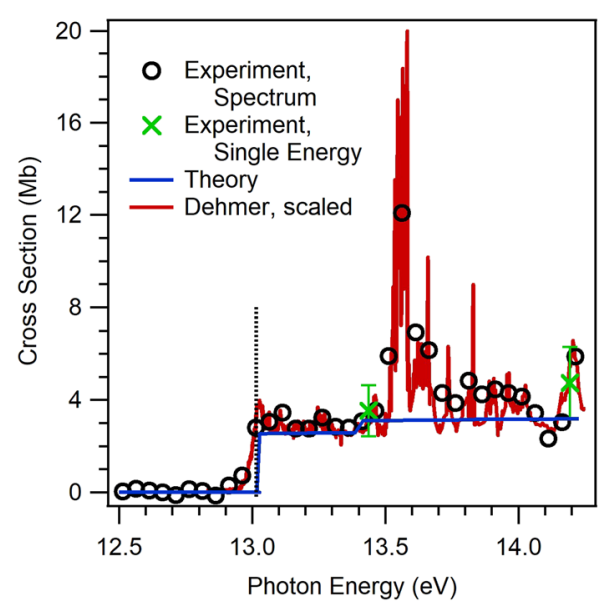

FIG. 6. Absolute photoionization spectrum of $\mathrm{OH}$. Open circles are the data obtained from the energy-dependent scan (Experiment 16) in the current work, scaled to the absolute cross section measurements made at 13.436 and $14.193 \mathrm{eV}$ (indicated with green x's, shown with error bars, as listed in Table III). The tabulated $\mathrm{OH}$ spectrum is reported in the supplementary material. The blue solid line is the theoretical spectrum obtained in this work (not scaled). The red line is the high-resolution $(\Delta E=3 \mathrm{meV})$ spectrum taken from the work of Dehmer, ${ }^{12}$ scaled to match the two absolute cross sections determined in this work (green x's). The dotted black line is the ionization energy of $\mathrm{OH}$.

that of $\mathrm{OH}$ because the $\mathrm{O}\left({ }^{3} P\right)$ atoms had a lower associated signal and existed over a shorter time window than the $\mathrm{OH}$ radicals.

\section{E. Computed cross section and spectrum}

Absolute photoionization cross sections were computed from EOM-EA-CCSD Dyson orbitals and a Coulomb wave description of the ionized electron. The results for $\mathrm{OH}$ and $\mathrm{O}\left({ }^{3} P\right)$ radicals are shown in Figs. 6 and 7, respectively. For $\mathrm{O}\left({ }^{3} P\right)$, the computed cross section rises rapidly at the threshold to $2.80 \mathrm{Mb}$ and then continues to rise very gradually over

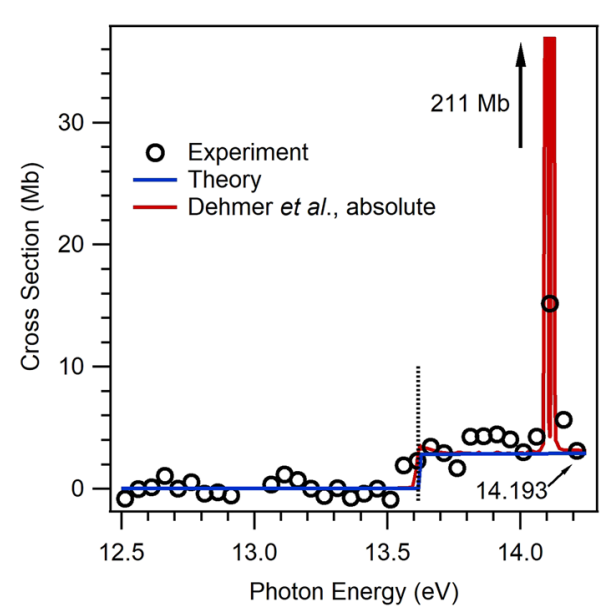

FIG. 7. Absolute photoionization spectrum of $\mathrm{O}\left({ }^{3} P\right)$. Shown here (black circles) is the absolute energy-resolved cross section of $\mathrm{O}\left({ }^{3} P\right)$ atoms formed in this experiment (Experiment 16), which was obtained by scaling the relative spectrum to the absolute cross section value from the literature at $14.193 \mathrm{eV} .^{60}$ The blue solid line is the theoretical spectrum obtained in this work. The red line is the digitized absolute photoionization spectrum of Dehmer et al. ${ }^{62}$ The dotted black line is the ionization energy of $\mathrm{O}\left({ }^{3} P\right)$. 
the next $0.7 \mathrm{eV}$ to around $2.9 \mathrm{Mb}$. As for $\mathrm{OH}$, the calculations also show a sudden rise in $\mathrm{OH}$ cross sections near the threshold to $2.5 \mathrm{Mb}$. There is another small sudden increase at ca. $13.4 \mathrm{eV}$, where the $\mathrm{O}-\mathrm{H}$ stretching $v^{+}=1$ vibrational level in the ionized state becomes energetically accessible. Note that our calculations do not include effects of autoionizing states, as discussed in more detail below.

\section{DISCUSSION}

\section{A. OH photoionization spectrum}

Figure 6 compares the $\mathrm{OH}$ photoionization spectrum measured in this work with the high-resolution $[\Delta E=0.23 \AA$ ( $3 \mathrm{meV}$ at $13 \mathrm{eV}$ )] spectrum reported by Dehmer ${ }^{12}$ (red line, scaled to match the current data). As observed by Dehmer ${ }^{12}$ and by Cutler et al., ${ }^{13}$ the photoionization spectrum increased rapidly at threshold, followed by a plateau, until reaching an intense feature centered at $13.55 \mathrm{eV}$ that has been assigned to a rotationally resolved band of the Rydberg series converging to the a ${ }^{1} \Delta$ excited state of $\mathrm{OH}^{+}$. Due to our lower energy resolution, the Rydberg autoionizing resonances at $13.6 \mathrm{eV}$, which are resolved as several peaks in Dehmer's spectrum, appeared as a single feature with a width of about $80 \mathrm{meV}$. The features we observed at 13.663, 13.813, and $14.213 \mathrm{eV}$ are all present as medium intensity features in the high-resolution literature spectra; however, they have not yet been assigned. ${ }^{12,13}$

The photoionization cross sections computed for $\mathrm{OH}$ from EOM-EA-CCSD Dyson orbitals are in good agreement with the spectra measured in this work (Fig. 6). There appear to be no significant resonances between 13.1 and $13.4 \mathrm{eV}$, so we compare the experimental and computed cross sections in this region. The average absolute cross section measured in the experimental spectrum (between 13.113 and $13.413 \mathrm{eV}$ ) is 2.7 $\pm 0.8 \mathrm{Mb}$. The average calculated cross section for $\mathrm{OH}$ over the same energy range is $2.6 \mathrm{Mb}$.

Both of the previous calculations for $\mathrm{OH}$ cover a broad range of photon energies, making it challenging to precisely compare their predictions with our results, which are confined to within $\sim 1.2 \mathrm{eV}$ above threshold. ${ }^{15,16}$ Nevertheless, digitizing the curve computed using the position form of the dipole moment in Fig. 3 of Stephens and McKoy provides a value of $\sim 3.3 \mathrm{Mb}$ at $14.0 \mathrm{eV}$ (the velocity form gives a somewhat higher value near $5 \mathrm{Mb}$ ), which is in good agreement with our calculated value of $3.2 \mathrm{Mb}$. Note that Stephens and McKoy employ a Hartree-Fock wave function and therefore are neglecting correlation effects in their calculations. Veseth and Kelly derive an absolute photoabsorption spectrum from the imaginary dynamic polarizability, computed by many-body perturbation theory, which includes correlation effects but requires the use of a model Hamiltonian. They find differences in the absolute total cross section when compared to Stephens and McKoy. However, it is unclear whether this difference stems from a difference between the photoabsorption and photoionization cross sections, correlation effects, or other methodological differences. We cannot compare our results directly with those of Veseth and Kelly because the computed absorption cross section at threshold is approximately $12 \mathrm{Mb}$ and is thus clearly dominated by non-ionization processes. The next point, at $2.7 \mathrm{eV}$ above threshold, is well beyond the range of photon energies studied in our work.

The computational approach used here describes direct photoionization and does not include features that arise due to excitation to metastable autoionizing states, such as those observed at $13.55,13.663,13.813$, and $14.213 \mathrm{eV}$. In addition, competing loss processes such as photon-energy dependent predissociation of $\mathrm{OH}$ were not considered in the calculation. In the limit that vibrational autoionization dominates the competing loss processes, conservation of oscillator strength through the energetic threshold of each cation vibrational state implies that there should be no increase in the ion yield at the $v^{+}=1$ threshold $(13.40 \mathrm{eV})$. Neither our experimental spectrum nor the higher resolution spectrum of Dehmer shows an increase in the cross section at $13.40 \mathrm{eV}$, where the FCF for $v^{+}=1$ has a magnitude that is $17 \%$ as large as the FCF for $v^{+}=0$. The lack of an observed step increase at $13.40 \mathrm{eV}$ implies that non-ionizing outcomes are of negligible importance in this region of the $\mathrm{OH}$ absorption spectrum.

\section{B. $O\left({ }^{3} P\right)$ photoionization spectrum}

The $\mathrm{O}\left({ }^{3} P\right)$ photoionization spectrum has been measured previously. ${ }^{60,62-78}$ The most recent absolute cross section measurements were by Angel and Samson, ${ }^{60}$ and the most recent photoionization spectrum was a high resolution relative spectrum taken by Dehmer et al. ${ }^{62}$ In 1992, Fennelly and Torr evaluated the literature, recommending that the absolute cross sections of Samson and co-workers be used in conjunction with the relative photoionization spectrum of Dehmer et al. Figure 7 (red line) shows the literature high-resolution spectrum, digitized from the work of Dehmer et al., ${ }^{62}$ and scaled at $14.25 \mathrm{eV}$ to the absolute cross section reported by Angel and Samson. ${ }^{60}$ We did not use the spectrum evaluated by Fennelly and Torr, ${ }^{66}$ for reasons discussed in the supplementary material.

Our experimental work relied on the $\mathrm{O}\left({ }^{3} P\right)$ photoionization cross section at $14.193 \mathrm{eV}$ as a reference for our $\mathrm{OH}$ cross section measurements, so we do not report new results for $\mathrm{O}\left({ }^{3} P\right)$. Figure 7 shows our current spectrum, scaled to the literature $\mathrm{O}\left({ }^{3} P\right)$ photoionization cross section of $3.1 \pm 0.3 \mathrm{Mb}$ at $14.25 \mathrm{eV}$, from Samson and co-workers. ${ }^{60,65}$ We have sufficient energy resolution to partially capture the strong resonance (at $14.113 \mathrm{eV}$ ) of the metastable autoionizing states observed by Dehmer and Chupka. ${ }^{63}$

Our computed cross sections for $\mathrm{O}\left({ }^{3} P\right)$ are in excellent agreement with the absolute cross sections reported by Angel and Samson ${ }^{60}$ (Fig. 7). These are also in good agreement with past theory. ${ }^{67-78}$ Again, our calculations do not reproduce the strong resonance at $14.113 \mathrm{eV}$, for the same reason discussed above for $\mathrm{OH}$. The resonance at $14.113 \mathrm{eV}$ is a Feshbach resonance state that belongs to the $n s^{\prime \prime}{ }^{3} P$ Rydberg series converging to the ${ }^{2} P^{0}$ state. ${ }^{62}$ Similarly, the sharp peak observed in the $\mathrm{OH}$ spectrum at $13.55 \mathrm{eV}$ is also a Feshbach resonance belonging to an $n d$ Rydberg series converging to the $\mathrm{a}^{1} \Delta$ state. $^{12}$ 


\section{CONCLUSION}

We report the first absolute VUV photoionization spectrum for the hydroxyl radical, based on discrete measurements of $\sigma(13.436 \mathrm{eV})=3.2 \pm 1.0 \mathrm{Mb}$ and $\sigma(14.193 \mathrm{eV})=4.7$ $\pm 1.6 \mathrm{Mb}$. These values are measured relative to the known cross section for $\mathrm{O}\left({ }^{3} P\right)$ at $14.193 \mathrm{eV}$, with xenon used as a transfer standard at $13.436 \mathrm{eV}$. The absolute photoionization spectrum will have practical importance for the measurement of product branching ratios and mole fraction determinations of $\mathrm{OH}$ via photoionization mass spectrometry in kinetics and flame studies. From a fundamental point of view, the experimental $\mathrm{OH}$ radical cross section is a tractable and important benchmark for computing molecular absolute photoionization cross sections from first principles. ${ }^{41,79-85}$ The calculations in this work employed Dyson orbitals computed from EOMCCSD wave functions and a Coulomb wave treatment of the photoelectron. Although both the initial and final states in $\mathrm{O}\left({ }^{3} P\right)$ and $\mathrm{OH}$ have open-shell character, we find that EOM-CC yields accurate Dyson orbitals. We believe EOMCC Dyson orbitals can generally be used for such open-shell systems, as long as there are no issues with spin contamination. Both EOM-IP and EOM-EA approaches worked equally well for the systems studied here, but as a general guideline we recommend using an approach that employs a reference without multi-configurational character (e.g., in the case of $\mathrm{O}$ and $\mathrm{OH}$, which would be EOM-EA). Finally, the results of this work demonstrate once again that a Coulomb wave provides a reasonable description of the continuum wave function for neutral atoms and small molecules with one heavy atom, as we found in an earlier study on closed-shell systems. $^{41}$

\section{SUPPLEMENTARY MATERIAL}

See supplementary material for further discussion of the initial ozone concentration determination, evaluation of the literature photoionization spectrum of $\mathrm{O}\left({ }^{3} P\right)$, observations of vibrationally excited $\mathrm{OH}$ radicals, calculations using different reference wave functions, the discussion of error analysis sources, and a tabulated $\mathrm{OH}$ photoionization spectrum.

\section{ACKNOWLEDGMENTS}

This research was supported by the National Science Foundation Grant No. CHE-1413712 and the National Aeronautics and Space Administration's (NASA) Upper Atmospheric Research Program Grant No. NNX12AE01G. A.I.K. acknowledges support by the United States Department of Energy, Basic Energy Sciences through the No. DE-FG0205ER15685 grant. L.G.D. was supported by an EPA STAR Fellowship and a Sandia Campus Executive Laboratory Directed Research and Development (LDRD) project. L.S. was supported by NASA Headquarters under the NASA Earth and Space Science Fellowship Program-Grant No. NNX14AO60H. The participation of D.L.O., J.D.S., and C.A.T. and the development and maintenance of the MPIMS apparatus are based upon work supported by the U.S. Department of Energy, Office of Science, Office of Basic Energy
Sciences. Sandia National Laboratories is a multi-mission laboratory managed and operated by National Technology and Engineering Solutions of Sandia, LLC., a wholly owned subsidiary of Honeywell International, Inc., for the U.S. Department of Energy's National Nuclear Security Administration under Contract No. DE-NA0003525. The views expressed in the article do not necessarily represent the views of the U.S. Department of Energy or the United States Government. The research conducted used resources of the Advanced Light Source, which is a DOE Office of the Science User Facility at Lawrence Berkeley National Laboratory under Contract No. DE-AC02-05CH11231.

${ }^{1}$ R. Atkinson and J. Arey, Chem. Rev. 103, 4605 (2003).

${ }^{2}$ D. E. Heard and M. J. Pilling, Chem. Rev. 103, 5163 (2003).

${ }^{3}$ B. J. Finlayson-Pitts and J. N. Pitts, Jr., Chemistry of the Upper and Lower Atmosphere: Theory, Experiments, and Applications (Academic Press, 1999)

${ }^{4}$ J. A. Miller, M. J. Pilling, and J. Troe, Proc. Combust. Inst. 30, 43 (2005).

${ }^{5}$ S. Weinreb, A. H. Barrett, M. L. Meeks, and J. C. Henry, Nature 200, 829 (1963).

${ }^{6}$ R. T. Wiedmann, R. G. Tonkyn, M. G. White, K. Wang, and V. McKoy, J. Chem. Phys. 97, 768 (1992).

${ }^{7}$ J. M. Dyke, S. D. Gamblin, A. Morris, J. B. West, and T. G. Wright, AIP Conf. Proc. 454, 81 (1998).

${ }^{8}$ J. D. Barr, A. De Fanis, J. M. Dyke, S. D. Gamblin, N. Hooper, A. Morris, S. Stranges, J. B. West, and T. G. Wright, J. Chem. Phys. 110, 345 (1999).

${ }^{9}$ J. B. West, J. M. Dyke, A. Morris, T. G. Wright, and S. D. Gamblin, J. Phys. B: At., Mol. Opt. Phys. 32, 2763 (1999).

${ }^{10}$ G. A. Garcia, X. Tang, J.-F. Gil et al., J. Chem. Phys. 142, 164201 (2015).

${ }^{11}$ S. Stranges, R. Richter, and M. Alagia, J. Chem. Phys. 116, 3676 (2002).

${ }^{12}$ P. M. Dehmer, Chem. Phys. Lett. 110, 79 (1984).

${ }^{13}$ J. N. Cutler, Z. X. He, and J. A. R. Samson, J. Phys. B: At., Mol. Opt. Phys. 28, 4577 (1995).

${ }^{14}$ F. Innocenti, L. Zuin, M. L. Costa, A. A. Dias, A. Morris, A. C. S. Paiva, S. Stranges, J. B. West, and J. M. Dyke, J. Electron Spectrosc. Relat. Phenom. 142, 241 (2005).

${ }^{15}$ J. A. Stephens and V. McKoy, J. Chem. Phys. 88, 1737 (1988).

${ }^{16}$ L. Veseth and H. P. Kelly, Phys. Rev. A 45, 4621 (1992).

${ }^{17}$ L. Veseth, Phys. Rev. A 44, 358 (1991).

${ }^{18}$ I. T. N. Jones and K. D. Bayes, J. Am. Chem. Soc. 94, 6869 (1972).

${ }^{19}$ M. Sablier and T. Fujii, Chem. Rev. 102, 2855 (2002).

${ }^{20}$ I. R. Slagle, F. Yamada, and D. Gutman, J. Am. Chem. Soc. 103, 149 (1981).

${ }^{21}$ I. R. Slagle and D. Gutman, J. Am. Chem. Soc. 107, 5342 (1985).

${ }^{22}$ R. S. Timonen, E. Ratajczak, D. Gutman, and A. F. Wagner, J. Phys. Chem. 91, 5325 (1987).

${ }^{23}$ C. Fockenberg, H. J. Bernstein, G. E. Hall, J. T. Muckerman, J. M. Preses, T. J. Sears, and R. E. Weston, Rev. Sci. Instrum. 70, 3259 (1999).

${ }^{24}$ A. J. Eskola and R. S. Timonen, Phys. Chem. Chem. Phys. 5, 2557 (2003).

${ }^{25}$ M. A. Blitz, A. Goddard, T. Ingham, and M. J. Pilling, Rev. Sci. Instrum. 78, 034103 (2007).

${ }^{26}$ M. T. Baeza-Romero, M. A. Blitz, A. Goddard, and P. W. Seakins, Int. J. Chem. Kinet. 44, 532 (2012).

${ }^{27}$ D. L. Osborn, P. Zou, H. Johnsen et al., Rev. Sci. Instrum. 79, 104103 (2008).

${ }^{28}$ C. A. Taatjes, N. Hansen, D. L. Osborn, K. Kohse-Hoinghaus, T. A. Cool, and P. R. Westmoreland, Phys. Chem. Chem. Phys. 10, 20 (2008).

${ }^{29}$ D. R. Lide, CRC Handbook of Chemistry and Physics (CRC Press, Boca Raton, Florida, 2003).

${ }^{30} \mathrm{~S}$. Willitsch, F. Innocenti, J. M. Dyke, and F. Merkt, J. Chem. Phys. 122, 024311 (2005).

${ }^{31}$ L. G. Dodson, L. Shen, J. D. Savee, N. C. Eddingsaas, O. Welz, C. A. Taatjes, D. L. Osborn, S. P. Sander, and M. Okumura, J. Phys. Chem. A 119, 1279 (2015).

${ }^{32}$ J. D. Savee, S. Soorkia, O. Welz, T. M. Selby, C. A. Taatjes, and D. L. Osborn, J. Chem. Phys. 136, 134307 (2012).

${ }^{33}$ O. Welz, J. D. Savee, D. L. Osborn, S. S. Vasu, C. J. Percival, D. E. Shallcross, and C. A. Taatjes, Science 335, 204 (2012).

${ }^{34}$ C. A. Taatjes, Int. J. Chem. Kinet. 39, 565 (2007).

${ }^{35}$ J. Linderberg and Y. Öhrn, Propagators in Quantum Chemistry (Academic Press, London, 1973). 
${ }^{36}$ J. V. Ortiz, Adv. Quantum Chem. 35, 33 (1999).

${ }^{37}$ C. M. Oana and A. I. Krylov, J. Chem. Phys. 127, 234106 (2007).

${ }^{38}$ B. T. Pickup, Chem. Phys. 19, 193 (1977).

${ }^{39}$ C. M. Oana and A. I. Krylov, J. Chem. Phys. 131, 124114 (2009).

${ }^{40}$ A. I. Krylov, Annu. Rev. Phys. Chem. 59, 433 (2008).

${ }^{41}$ S. Gozem, A. O. Gunina, T. Ichino, D. L. Osborn, J. F. Stanton, and A. I. Krylov, J. Phys. Chem. Lett. 6, 4532 (2015).

${ }^{42}$ M. J. Abplanalp, S. Gozem, A. I. Krylov, C. N. Shingledecker, E. Herbst, and R. I. Kaiser, Proc. Natl. Acad. Sci. U. S. A. 113, 7727 (2016).

${ }^{43}$ A. O. Gunina and A. I. Krylov, J. Phys. Chem. A 120, 9841 (2016).

${ }^{44}$ S. Gozem and A. I. Krylov, ezDyson, http://iopenshell.usc.edu/downloads/ ezdyson, 2016.

${ }^{45}$ Y. Shao, Z. Gan, E. Epifanovsky et al., Mol. Phys. 113, 184 (2015).

${ }^{46}$ J.-D. Chai and M. Head-Gordon, Phys. Chem. Chem. Phys. 10, 6615 (2008).

${ }^{47}$ V. Mozhayskiy and A. I. Krylov, ezSpectrum User's Manual, http://iopenshell.usc.edu/downloads/, 2009.

${ }^{48}$ Y. Matsumi and M. Kawasaki, Chem. Rev. 103, 4767 (2003).

${ }^{49}$ R. Atkinson, D. L. Baulch, R. A. Cox, J. N. Crowley, R. F. Hampson, R. G. Hynes, M. E. Jenkin, M. J. Rossi, and J. Troe, Atmos. Chem. Phys. 4, 1461 (2004).

${ }^{50}$ S. P. Sander, J. Abbatt, J. R. Barker et al., JPL Publication 10-6 (2011).

${ }^{51}$ J. C. Ianni Kintecus, Windows Version 2.80, http://www.kintecus.com, 2002.

${ }^{52}$ K. H. Gericke, F. J. Comes, and R. D. Levine, J. Chem. Phys. 74, 6106 (1981).

${ }^{53}$ F. J. Comes, K. H. Gericke, and J. Manz, J. Chem. Phys. 75, 2853 (1981).

${ }^{54}$ J. E. Butler, L. D. Talley, G. K. Smith, and M. C. Lin, J. Chem. Phys. 74, 4501 (1981).

${ }^{55}$ W. A. Guillory, K. H. Gericke, and F. J. Comes, J. Chem. Phys. 78, 5993 (1983).

${ }^{56}$ C. B. Cleveland and J. R. Wiesenfeld, J. Chem. Phys. 96, 248 (1992).

${ }^{57}$ D. G. Sauder, J. C. Stephenson, D. S. King, and M. P. Casassa, J. Chem. Phys. 97, 952 (1992).

${ }^{58}$ D. C. McCabe, B. Rajakumar, P. Marshall, I. W. M. Smith, and A. R. Ravishankara, Phys. Chem. Chem. Phys. 8, 4563 (2006).

${ }^{59}$ L. D'Ottone, D. Bauer, P. Campuzano-Jost, M. Fardy, and A. J. Hynes, Phys. Chem. Chem. Phys. 6, 4276 (2004).

${ }^{60}$ G. C. Angel and J. A. R. Samson, Phys. Rev. A 38, 5578 (1988).

${ }^{61}$ J. A. R. Samson and W. C. Stolte, J. Electron Spectrosc. Relat. Phenom. 123, 265 (2002).
${ }^{62}$ P. M. Dehmer, J. Berkowitz, and W. A. Chupka, J. Chem. Phys. 59, 5777 (1973).

${ }^{63}$ P. M. Dehmer and W. A. Chupka, J. Chem. Phys. 62, 584 (1975).

${ }^{64}$ P. M. Dehmer, W. L. Luken, and W. A. Chupka, J. Chem. Phys. 67, 195 (1977).

65 J. A. R. Samson and P. N. Pareek, Phys. Rev. A 31, 1470 (1985).

${ }^{66}$ J. A. Fennelly and D. G. Torr, At. Data Nucl. Data Tables 51, 321 (1992).

${ }^{67}$ R. J. W. Henry, Planet. Space Sci. 16, 1503 (1968).

${ }^{68}$ A. F. Starace, S. T. Manson, and D. J. Kennedy, Phys. Rev. A 9, 2453 (1974).

${ }^{69}$ E. R. Smith, Phys. Rev. A 13, 1058 (1976).

${ }^{70}$ K. T. Taylor and P. G. Burke, J. Phys. B: At., Mol. Opt. Phys. 9, L353 (1976).

${ }^{71}$ A. K. Pradhan, J. Phys. B: At., Mol. Opt. Phys. 11, L729 (1978).

${ }^{72}$ A. K. Pradhan, Planet. Space Sci. 28, 165 (1980).

${ }^{73}$ G. A. Vesnicheva, G. M. Malyshev, V. F. Orlov, and N. A. Cherepkov, Zh. Tekh. Fiz. 56, 665 (1986).

${ }^{74}$ V. F. Orlov, N. A. Cherepkov, and L. V. Chernysheva, Opt. Spektrosk. 64, 683 (1988).

${ }^{75}$ K. L. Bell, K. A. Berrington, P. G. Burke, A. Hibbert, and A. E. Kingston, J. Phys. B: At., Mol. Opt. Phys. 23, 2259S (1990).

${ }^{76}$ C. T. Chen and F. Robicheaux, Phys. Rev. A 50, 3968 (1994).

${ }^{77}$ J. Berkowitz, J. Phys. B: At., Mol. Opt. Phys. 30, 583 (1997).

${ }^{78}$ S. S. Tayal, Phys. Rev. A 65, 032724 (2002).

${ }^{79}$ G. Fronzoni, M. Stener, and P. Decleva, Chem. Phys. 298, 141 (2004).

${ }^{80}$ A. P. P. Natalense and R. R. Lucchese, J. Chem. Phys. 111, 5344 (1999).

${ }^{81}$ I. Cacelli, R. Moccia, and A. Rizzo, Phys. Rev. A 57, 1895 (1998).

${ }^{82}$ J. Cukras, P. Decleva, and S. Coriani, J. Chem. Phys. 141, 174315 (2014).

${ }^{83}$ J. Cukras, S. Coriani, P. Decleva, O. Christiansen, and P. Norman, J. Chem. Phys. 139, 094103 (2013).

${ }^{84}$ M. Ruberti, R. Yun, K. Gokhberg, S. Kopelke, L. S. Cederbaum, F. Tarantelli, and V. Averbukh, J. Chem. Phys. 139, 144107 (2013).

${ }^{85}$ M. Ruberti, V. Averbukh, and P. Decleva, J. Chem. Phys. 141, 164126 (2014).

${ }^{86}$ R. Forster, M. Frost, D. Fulle, H. F. Hamann, H. Hippler, A. Schlepegrell, and J. Troe, J. Chem. Phys. 103, 2949 (1995).

${ }^{87}$ J. V. Michael, M. C. Su, J. W. Sutherland, J. J. Carroll, and A. F. Wagner, J. Phys. Chem. A 106, 5297 (2002).

${ }^{88}$ R. E. Huie, J. T. Herron, and D. D. Davis, J. Phys. Chem. 76, 2653 (1972). 